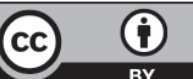

https://creativecommons.org/licenses/by/4.0/

\title{
DESARROLLO E IMPLEMENTACIÓN DE UNA APLICACIÓN WEB Y MÓVIL PARA LA SOLICITUD DE MÚSICOS EN BOGOTÁ - MUSICAPP
}

\author{
The development and the implementation of a web and a mobile \\ app upon the request of the musicians in bogotá
}

ÓSCAR ENRIQUE LÓPEZ GUEVARA ${ }^{1}$, JHON EDISON RABA FORERO ${ }^{2}$, NICOLÁS TURGA MALAGÓN ${ }^{3}$

Recibido:20 de noviembre de 2018. Aceptado:12 de diciembre de 2018

DOI: http://dx.doi.org/10.21017/rimci.2019.v6.n11.a59

\begin{abstract}
Resumen
MusicApp se presenta como una propuesta desde el programa de ingeniería de sistemas de la Corporación Universitaria Republicana, en donde se evidencia la aplicación de los procesos académicos que se han llevado a cabo como estudiantes para enfrentar un problema mediante una solución de base tecnológica. El siguiente documento es el resultado de procesos conceptuales y técnicos que permitieron analizar, diseñar y programar una aplicación que se planeó y desarrolló como opción de grado mediante la modalidad de monografía.
\end{abstract}

Palabras clave: Aplicación, móvil, web, seguridad.

\section{Abstract}

MusicApp was presented as a proposal of the systems engineering program of the Republican University Corporation, where the application of the academic processes that have been carried out as students to face a problem through a technology-based solution is evident. The following document is the result of conceptual and technical processes that allowed us to analyze, design and program an application that can be developed through the monograph modality.

Keywords: Web application, web services, web music services, musical services on a mobile, MVC, technology-based development.

\section{INTRODUCCIÓN}

L

A ERA DIGITAL nos ha ofrecido múltiples plataformas que reducen tiempo y costos a la hora de realizar diferentes actividades del día a día, otorgando beneficios y alternativas que están encaminadas a mejorar la calidad de vida de las personas, permitiendo el acceso a bienes y servicios desde la comodidad y la inmediatez que presupone tener un dispositivo móvil, en ese sentido el objetivo y el desarrollo de este documento está enfocado en mostrar como en la actualidad los habitantes de Bogotá, Colombia solicitan servicios musicales según sus preferencias, y cómo se pretende reducir el tiempo de búsqueda de servicios musicales al eliminar los desplazamientos que los usuarios realizan con el fin de encontrar este tipo de servicios, además de reunir a los músicos en una misma red que les permita ampliar su segmento del mercado por medio de una aplicación web y móvil llamada MusicApp.

1 Ingeniero de Sistemas de la Corporación Universitaria Republicana. Correo electrónico: oscarlopezbs@hotmail.com

2 Ingeniero de Sistemas de la Corporación Universitaria Republicana. Correo electrónico: jhon.raba93@gmail.com

3 Ingeniero de Sistemas de la Corporación Universitaria Republicana. Correo electrónico: nicolasturga@hotmail.com 
La aplicación está dirigida a músicos con residencia en Bogotá, o que trabajen en la ciudad, y a los clientes potenciales que puedan tener; puede ser cualquier ciudadano que se encuentre en el perímetro de la ciudad. Se hacen distinciones entre cada tipo de usuario.

MusicApp estará disponible para dispositivos Android y su vez en la web, para el caso de los músicos, allí se encontrará un formulario de registro para los músicos donde se requerirán los siguientes datos para hacer exitosa su contratación: nombre de la agrupación o del solista, nombre de representante de la agrupación, número de contacto, contraseña, correo electrónico, género musical de especialidad (estarán todos los géneros disponibles, para todos los gustos). Para los clientes, los datos requeridos en el formulario serán: nombres y apellidos, correo, teléfono, dirección y contraseña. Los dos roles podrán adjuntar una imagen de perfil para crear más fiabilidad en la relación cliente-músico. Después de haber registrado los datos, generará un perfil para cada agrupación o solista. Allí podrán anexar enlaces de sus redes sociales, tendrán la posibilidad de estipular sus precios según consideren, por tiempo, por integrantes, ocasión, desplazamiento, horario, y así las personas puedan escoger lo que se acomode a su presupuesto. También podrán ser notificados de las reservas que les hacen, y tendrán la potestad de aceptar o no la presentación.

Los clientes tendrán la posibilidad de ver toda la oferta de músicos, ya que estarán clasificados por géneros musicales, lo cual servirá para la toma de la decisión más acertada teniendo en cuenta precios y disponibilidad. La aplicación solo brindará el espacio para la publicación de la información y todo lo relacionado al contacto, más no se hace responsable de ausencias o de faltas a la hora de hacer la solicitud.

Para determinar los criterios antes mencionados, y que en el desarrollo del documento se desglosarán, se hizo un levantamiento de información mediante encuestas, donde se definió cuáles eran los criterios de búsqueda de los clientes a la hora de solicitar un músico, y los medios que usan los músicos para hacer publicidad del trabajo, además de una serie de preguntas que indicarán qué quería ver un cliente, y a su vez, qué quería mostrar el músico para que fuese más apetecido.
MusicApp nace y pretende ser una ayuda adicional a lo que otras herramientas tecnológicas puedan brindar, pues cabe resaltar que el objetivo también es que agremie a un sector de la economía que está disperso, donde no hay una relación sustancial entre donde buscan los clientes y donde los músicos pretenden crear un nicho de mercado. En ese sentido, MusicApp es una solución a una situación problemática real, pues va en la búsqueda de mejorar tiempos de cotización, contacto y servicio con el fin de garantizar que las solicitudes hacia los músicos no se queden en simples cotizaciones y se puedan materializar en servicios efectivos.

\section{Planteamiento del Problema}

En la actualidad no existe un método adecuado que permita mejorar el tiempo utilizado por las personas a la hora de requerir un servicio musical (bien sea de carácter familiar, o una presentación para amenizar una reunión empresarial), esto ocasiona que la metodología para buscar y solicitar un músico sea demorada, puesto que en algunos casos, implica que la persona interesada tenga que desplazarse hasta determinados puntos de la ciudad de Bogotá o verse en la obligación de buscar en directorios telefónicos algún grupo que se acomode al dinero que tiene destinado para la función.

Esto se convierte en una problemática, ya que se retrasa la gestión y la logística de un evento, por grande o pequeño que este sea, debido a que la música es parte fundamental en la organización de algún espectáculo, sea una cena, un cumpleaños, un desayuno o una obra de teatro; siempre va a estar presente, por lo cual, el ayudar a reducir tiempo a la hora de solicitar un servicio, puede reducir el tiempo que se usa para buscar a los músicos empleándolo en otros aspectos del evento, o simplemente queda saldada la necesidad de tener que desplazarse, llamar y posiblemente perder tiempo valioso buscando músicos que se acomoden a lo que se puede pagar y en el formato que lo quiera.

Por otro lado, se tiene a los músicos que, para el caso colombiano, han sido catalogados como una profesión de segunda, puesto que ni SAYCO que es una entidad que aboga por la propiedad 
intelectual y todos los derechos de autor que se puedan generar alrededor de los artistas musicales en Colombia, se ha puesto a la tarea de impulsar el mercado en el país, lo cual genera que un músico independiente no pertenezca a una entidad que los agremie[1]. Ricardo Quintero, ex vocalista de Lucho Bermúdez (gran exponente de nuestro folclor) y que actualmente hace parte la orquesta de La 14 cuenta que alcaldes han llegado a ofrecerles bebidas alcohólicas como parte de pago por su presentación. Por otro lado, Carlos Santofimio, otro músico de la Orquesta La 14 afirma que ni siquiera en los bancos les dan créditos, pues afirma él que: "Cuando se va a pedir un préstamo y uno cuenta a qué se dedica, casi que le cierran la puerta en la cara"[1]. Algunos llegan al punto de estudiar otras disciplinas, pues la pasión y la dedicación que le otorgan a la música no alcanzan a ser tan impactante, para que los valoren como profesionales.

Es de vital importancia impulsar campañas y eventos que muestren las propuestas artísticas en la ciudad, para que se promueva la cultura y el arte, pues no solo aplica para el sector musical, sino en otras áreas. Agrupaciones como Monsieur Periné, que actualmente son de talla internacional, empezaron como artistas independientes gestionando todo lo que implica tener una banda, lograron ser músicos de Sony Music Entertainment Colombia S. A; en ese sentido, lo que se pretende con la aplicación, es que así como Monsieur Periné logró tener un impacto de manera clandestina hasta llegar a ganar un Grammy gracias a su talento, los demás músicos que quieran tener un futuro profesional como ellos, o simplemente crear un público más grande haciendo su música de manera clandestina o independiente, se masifiquen con el fin de empezar a crear un mercado musical de todos los géneros, no solo de lo más popular, sino que todos las propuestas puedan ser escuchadas y valoradas de la misma manera.

\section{III. ОвJETIVOS}

\section{A. Objetivo General}

Desarrollar un prototipo de una aplicación web y móvil que permita facilitar el proceso de solicitud de músicos en Bogotá, ahorrando tiempo y costos de desplazamiento.

\section{B. Objetivos Especificos}

- Realizar un levantamiento de información mediante encuestas aplicadas a los músicos, y clientes que permitan conocer los gustos y métodos que se usan para solicitar músicos y sus servicios en Bogotá.

- Analizar los datos obtenidos en las encuestas para realizar la estructura del modelo de entidad relación para la base de datos.

- Diseñar la interfaz gráfica (Mockup) para considerar todas las interacciones posibles de los usuarios con la aplicación.

- Desarrollar un prototipo de una aplicación web y móvil junto con la documentación pertinente.

- Permitir la conexión entre músicos y el público en general por medio del celular y desde el computador, programando los elementos correspondientes tanto del lado del servidor como del lado del cliente para un entorno web y móvil.

\section{JUSTIFICACIÓN}

La aplicación en general nace de la necesidad de reducir tiempos a la hora de solicitar un músico para cualquier tipo de evento, permitiéndole a los clientes tener una oferta bastante amplia en cuanto a agrupaciones y géneros musicales que se acomode a sus necesidades y capacidades económicas, teniendo en cuenta el auge de nuevas tendencias a nivel musical, se generan otro tipo de públicos que siempre estarán dispuestos a escuchar nuevas propuestas y querer escucharlos en vivo o como se mencionaba anteriormente, hagan parte de eventos de diferente índole.

Una ventaja que justifica el desarrollo de esta aplicación es que esta se convierte en una apuesta que puede ayudar a garantizar el valor del trabajo del otro, viendo esto reflejado económicamente en los ingresos de los músicos y en la satisfacción de quien los solicite (clientes). Los clientes podrán hacer reservas de los músicos; pues al hacerlo con anterioridad al día requerido y con un tiempo pertinente para la cancelación de la presentación, en 
el caso de que suceda, hará más profesional la labor del músico, llevándolo a planear su trabajo de tal forma que pueda organizar su tiempo. Los músicos se podrán ver beneficiados también porque estarán reunidos en una plataforma (que si bien es para ofrecer servicios de entretenimiento, también servirá como un vínculo de valor entre la relación cliente-músico), convirtiéndose así en una red de empleo para los mismos, garantizando que las agrupaciones allí registradas, puedan hacer público el precio por presentación, duración, trayectoria (o descripción del grupo), número de integrantes (o si es solista), así como las redes sociales donde tengan una cuenta para que los clientes puedan hacer seguimiento de su trabajo en caso de que lo deseen.

Se va a tener también la facilidad de hacerlo desde casa, que es muy importante, porque la idea de las nuevas tecnologías es poder reducir tiempos, disminuyendo los desplazamientos, luego que es uno de los principales objetivos a lograr con la aplicación móvil, ya que todo se hará más sencillo desde la comodidad del hogar o desde el lugar de trabajo donde se hará la solicitud para un mismo día o la reservación previa de la presentación. La aplicación va a estar abierta a cualquier género musical, no se va a discriminar ningún género, pues la idea es que los clientes tengan un gran catálogo de agrupaciones donde puedan escoger a libertad, pretendiendo lograr que los músicos no se vean rezagados a la hora de ser contratados, sino que esté abierta a la pluralidad que, como arte, es lo que la caracteriza.

\section{Marco Teórico}

\section{A. Estado del Arte}

En Colombia han surgido ideas desde el ámbito tecnológico para darle un orden o cambiar el modelo de negocio para prestar estos servicios en los cascos urbanos. Se tienen ejemplos de páginas web como: lavitrola.com.co, que se define como: "Somos una empresa dedicada 100\% a brindarte los mejores músicos para tus eventos, músicos profesionales con gran experiencia y amplia trayectoria en el medio, para eventos empresariales, así como para eventos privados (cualquier tipo de evento social), explorando nuevas tendencias de música moderna y tradicional"[2]. El contacto con
La Vitrola se hace por medio de un formulario de contacto. Se asumió que funciona como intermediario, y de esa manera se agendan los servicios que los músicos ofrezcan. Un segundo ejemplo es tutoque.co[3], que tiene una interfaz gráfica amigable, contiene pago vía internet, tiene un formulario donde hay criterios para solicitar los servicios, tales como duración, formato y lugar. Se desconoce la forma como genera el precio, pero el sistema lo hace automáticamente. No está disponible el registro para hacer una exploración más amplia respecto al funcionamiento, aunque si tiene una zona para cotización, la cual se llama: 'Asesoría personalizada'. Luego viene amenizarmusicapara elexito.com[4], donde se encuentra la siguiente descripción: "En AMENIZAR, encuentras la mejor opción en servicios musicales con excelentes profesionales que harán de tu evento una experiencia inolvidable. AMENIZAR reúne a jóvenes y talentosos músicos bajo la dirección de Jairo Guerrero. Licenciado en Música de la Universidad Pedagógica Nacional con más de 30 años de experiencia en 'amenización' musical de eventos, ceremonias y actividades especiales." [4]. Esta página se basa en el servicio de cotización. Cuenta con una zona de contacto, donde se requieren unos datos para diligenciar una cotización.

Por otro lado, quieromusicos.com[5] dice: “QuieroMusicos es la primera agencia de booking de artistas colombiana basada en una plataforma web, que le permite a las empresas y personas interesadas en contratar artistas para sus eventos, acceder a un amplio portafolio con gran variedad de artistas de primera calidad en múltiples géneros musicales, incluyendo propuestas verdaderamente únicas, en virtud de la originalidad y la singularidad de su repertorio y puesta en escena"[5]. Esta plataforma también usa la cotización como medio de negocio; es evidente en su página de inicio que su fuerte son las empresas, pues hacen énfasis en las instituciones que hacen uso de la plataforma, como muestra de su influencia para adherir más cliente, no solo corporativos. En la ciudad de Cali, Colombia la aplicación móvil Serenatapp[6], se enfoca en cotizar los servicios, enviando mensajes y dando esperas de hasta 48 horas para obtener una respuesta vía correo electrónico, lo que extiende el tiempo para concretar un servicio. La aplicación no se encuentra disponible en ninguna tienda virtual para descargar vía teléfono inteligente. 
El caso de musicosyserenatas.com, ellos se describen como: "Ser la agencia líder de eventos musicales, la cual cuenta con artistas profesionales y capacitados para eventos especiales a nivel nacional. Satisfacer las necesidades de nuestros clientes, brindándoles un producto de calidad y con un excelente servicio. Desarrollar de forma creativa e innovadora nuestros eventos. Actuar siempre en forma ética, veraz y comprometida para nuestros clientes"[8], permite el pago vía internet, pero el contacto es independiente al pago del servicio, además carece de una descripción de los servicios que se pretenden ofrecer, tampoco cuenta con alguna versión móvil para Android o iOS. En Latinoamérica se encontraron aplicaciones en México, estas se centran en el nicho de mercado de la música ranchera, una de ella en fase beta (Mis Mariachis), se definen como: “La primera aplicación para pedir mariachis desde tu Smartphone, de manera fácil, rápida y segura" [8], cuenta con un registro para cliente y uno para mariachis. La otra aplicación es Mariappchi que: “...es la nueva manera de pedir mariachis y serenatas en México. ¿Tendrás un evento? ¿Quieres sorprender a una chica? Te brindamos una experiencia inolvidable al alcance de un click"[9], están en circulación en el App Store de forma gratuita. Esta última tiene un impacto fuerte en el mercado gracias a que funcionan en tiempo real, pero está limitada a solo un gremio en particular. También se pueden encontrar servicios musicales alojados en aplicaciones como Mercado Libre[10], Olx[11] o productoras independientes. RAMASSO Productora[12]. Los crowdfunding también hacen parte del mercado musical, en ese sentido, Busk es el que mejores prebendas tiene para los artistas, como para su división de música. Esta aplicación web y móvil de origen irlandés trabaja en todo el mundo, y funciona como canal entre organizadores de eventos, 'fans' y artistas. Busk propone: "Tomamos una tasa más baja que la mayoría (solo 10\%) sin tarifas iniciales o tasa de suscripción anual, y las personas también pueden usar sus perfiles para hacerse fan, recibir pagos sin efectivo e incluso contratarlo para conciertos, directamente desde su perfil. Ningún otro servicio de música proporciona todo lo anterior. Ah, sí, y somos una empresa social que hace trabajo de incidencia en nombre de artistas callejeros. Por lo tanto, vender música a través de nosotros no solo es más barato para ti, sino que también apoya una buena causa"[13].
El escenario, es prometedor para los mexicanos (caso del mariachi) y para los artistas callejeros (no solo músicos), pues como se indica anteriormente en México, la aplicación solo está orientada para un género musical y en Colombia, aunque 2 permiten el pago por internet, no es muy claro cómo se generan los precios, y cómo se relaciona el pago con el servicio que se adquiere, para el caso de tutoque.co[3], y musicosyserenatas.com[7] respectivamente. Los demás casos solo permiten realizar una cotización; esto no reduce tiempos a la hora de concretar un servicio, todo lo contrario, genera más iteraciones en cuanto a la negociación. Lo cual da cabida a preguntar, ¿Qué pasa si necesito un servicio en este preciso momento? Viendo que las tecnologías actuales del mercado no permiten la interacción en tiempo real, la persona, se ve en la necesidad de elegir muchas veces un músico sin conocer que ofrece y la calidad de su trabajo o en el peor de los casos, tener que desplazarse hasta el punto de encuentro y reunión de los músicos.

\section{B. Conceptos y términos}

Móldelo Entidad Relación: El modelo entidad relación $(E / R)$ proporciona una herramienta para representar información del mundo real a nivel conceptual. Creado en 1976 por Peter Chen, permite describir las entidades involucradas en una base de datos, así como las relaciones y restricciones de ellas[14].

UML: El lenguaje UML es un estándar OMG (Object Management Group) diseñado para visualizar, especificar, construir y documentar software orientado a objetos[15].

Diagrama de casos de uso: Es una interacción típica entre un usuario y un sistema de cómputo[16].

El Modelado de casos de uso es un método orientado a los usuarios para identificar necesidades funcionales de un nuevo sistema de información. El modelado de casos de uso es una técnica que permite modelar las funciones de un sistema en términos de eventos, de quién inicia los eventos, y de cómo responde a estos eventos, fue introducido por Ivar Jacobson en 1986 y popularizado en 1992 tras la publicación del libro: 'Ingeniería de Software orientado a Objetos: Una aproximación basada en casos de uso'[17]. 
Diagrama de secuencia: Un diagrama de secuencias muestra la interacción de un conjunto de objetos de una aplicación a través del tiempo, en el cual se indicarán los módulos o clases que formaran parte del programa y las llamadas que se hacen cada uno de ellos para realizar una tarea determinada, por esta razón permite observar la perspectiva cronológica de las interacciones. Es importante recordar que el diagrama de secuencias se realiza a partir de la descripción de un caso de uso[18].

Aplicación web: Una aplicación web es una aplicación informática distribuida cuya interfaz de usuario accesible desde un cliente web, normalmente un navegador web[19].

Son aquellas aplicaciones que los usuarios pueden utilizar accediendo a un servidor web a través de internet o de una intranet mediante un navegador. En otras palabras, es una aplicación software que se codifica en un lenguaje soportado por los navegadores web, y en la que se confía la ejecución de la aplicación al navegador[20].

Aplicación móvil: Es aquel software que se utiliza en un dispositivo móvil como herramienta de comunicación, gestión, venta de servicios-productos orientados a proporcionar al usuario las necesidades que demande de forma automática e interactiva[21].

Javascript: Es un lenguaje de programación interpretado, por lo que no es necesario compilar los programas para ejecutarlos. En otras palabras, los programas escritos con Javascript (scripts) se pueden probar directamente en cualquier navegador sin necesidad de procesos intermedios[22].

Estos scripts normalmente consisten en unas funciones que son llamadas desde el propio HTML cuando algún evento sucede. De ese modo, podemos añadir efectos como que un botón cambie de forma al pasar el ratón por encima, o abrir una ventana nueva al pulsar en un enlace[23].

HTML: Es el lenguaje con el que se define el contenido de las páginas web. Básicamente se trata de un conjunto de etiquetas que sirven para definir el texto y otros elementos que compondrán una página web, como imágenes, listas, vídeos, etc[24].
PHP: (Cuyo nombre es acrónimo de PHP: Hipertext Preprocessor) Es un lenguaje interpretado con una sintaxis similar a la de $\mathrm{C}++$ o JAVA. Aunque el lenguaje se puede usar para realizar cualquier tipo de programa, es en la generación dinámica de páginas web donde ha alcanzado su máxima popularidad. En concreto, suele incluirse incrustado en páginas HTML (o XHTML), siendo el servidor web el encargado de ejecutarlo[25].

CSS: Es un lenguaje de hojas de estilos creado para controlar el aspecto o presentación de los documentos electrónicos definidos con HTML y XHTML. CSS es la mejor forma de separar los contenidos y su presentación y es imprescindible para crear páginas web complejas[26].

MySQL: Es un sistema gestor de bases de datos. Pero la virtud fundamental y la clave de su éxito es que se trata de un sistema de libre distribución y de código abierto. Lo primero significa que se puede descargar libremente de internet (por ejemplo de la dirección (www.mysql.com); lo segundo (código abierto) significa que cualquier programador puede remodelar el código de la aplicación para mejorarlo. Esa es también la base del funcionamiento del sistema Linux, por eso MySQL se distribuye fundamentalmente para Linux, aunque también hay versiones para Windows o Mac[27].

Android Studio: Android Studio es la plataforma oficial para el desarrollo de aplicaciones bajo el sistema operativo Android, incluye todo lo que necesita para crear diversas aplicaciones[28].

AJAX: Es un acrónimo de 'Asynchronous JavaScript $+X \mathrm{XL}^{\prime}$, que se puede traducir como «JavaScript asíncrono + XML». AJAX permite mejorar completamente la interacción del usuario con la aplicación, evitando las recargas constantes de la página, ya que el intercambio de información con el servidor se produce en un segundo plano[29].

JSON: Es el acrónimo de 'JavaScript Object Notation', JSON es un formato alternativo de envío y recepción de datos, para algunos casos, remplaza a XML o se usa para el envío de texto plano. Este formato de datos es más liviano que XML y hace el código más sencillo ya que utiliza código JavaScript como modelo de datos[30].

Rev. Ingeniería, Matemáticas y Ciencias de la Información Vol. 6 / Núm. 11 / enero - junio de 2019; pág. 
Método POST: Este método sólo se puede usar con formularios, y la información no se envía por la URL, sino que es invisible al usuario, se usa para enviar grandes campos de texto, subir imágenes, para no distorsionar las URL, esto lo hace amigable con una colección de variables[31].

Modelo-Vista-Controlador (MVC): El MVC es un patrón de arquitectura de software que separa los datos y la lógica de negocio de una aplicación de la interfaz de usuario y el módulo encargado de gestionar los eventos y las comunicaciones. Para ello MVC propone la construcción de tres componentes distinto para la representación de la información, y por otro lado para la interacción del usuario. Este patrón se basa en la idea de reutilización de código y la separación de conceptos, características que buscan facilitar la tarea de desarrollo de aplicación y su posterior mantenimientos[32].

Activity: Una Activity es un componente de la aplicación que contiene una pantalla con la que los usuarios pueden interactuar para realizar una acción, como marcar un número telefónico, tomar una foto, enviar un correo electrónico o ver un mapa. A cada actividad se le asigna una ventana en la que se puede dibujar su interfaz de usuario. La ventana generalmente abarca toda la pantalla, pero en ocasiones puede ser más pequeña que esta y quedar «flotando» encima de otras ventanas[28].

\section{Marco Metodológico}

La modalidad que se usará en el desarrollo de este proyecto es de campo y está basada en el tipo investigación descriptiva ya que se analizará la metodología de contratación de músicos utilizada actualmente en Bogotá, identificando así sus ventajas y desventajas en cuanto a tiempos, procesos, efectividad y cumplimiento a la hora de prestar o adquirir un servicio musical, para de esta manera poder mejorarla con la ayuda de una aplicación web y móvil.

La metodología que se ha elegido para el desarrollo de la aplicación es de tipo cascada, ya que permite tener control de cada una de las fases del proyecto de forma independiente y se llevara a cabo con la siguiente estructura; análisis de requerimientos, diseño, desarrollo, implementación y pruebas.
El grupo objetivo de este proyecto como bien se pudo haber resaltado anteriormente son las personas que deseen contratar alguna presentación musical y los músicos que presten estos servicios en Bogotá. Es una población que se caracteriza por ser finita, pero de crecimiento exponencial. Para el levantamiento y análisis de información se realizarán 4 métodos de la siguiente manera: Encuestas, Observación directa, Apprenticing y Requirements Workshops.

Para el diseño de la aplicación se utilizará la metodología lenguaje de modelado unificado (UML) que nos permitirá tener una estructura definida de cómo se comportan las variables y la relación entre los usuarios finales de la aplicación, para luego comenzar con la fase de desarrollo.

La recolección de los datos se hizo por medio de una encuesta. Se formularon 16 preguntas para los músicos, y 12 preguntas para clientes. Se usó la herramienta de Google Formularios para hacer la encuesta. Toda la logística para convocar a los encuestados se hizo por medio de redes sociales. La encuesta se realizó teniendo en cuenta las redes sociales Facebook y WhatsApp, la cual circuló por 11 días desde el 18 de julio de 2017 hasta el 29 de julio de 2017 obteniendo un total de 73 músicos encuestados, todos de forma virtual.

Cabe aclarar, que la cantidad de músicos en la ciudad de Bogotá no cuenta con una cifra exacta. Al hacer una inspección en Facebook, sobre grupos activos donde los músicos interactúan, se encontraron alrededor de 40, con una suma aproximada de 20.000 músicos.

El mínimo de encuestas se determinó por medio de la siguiente fórmula (Herrera, 2011):

Fórmula de la encuesta:

$$
n=\frac{N * Z_{\alpha}{ }^{2} p * q}{d^{2} *(N-1)+Z_{\alpha}{ }^{2} * p * q}
$$

Donde:

- $\mathrm{N}$ = Total de la población

- $\mathrm{Z}_{\alpha}=1.96$ al cuadrado (si la seguridad es del $95 \%$ )

- $\mathrm{p}=$ proporción esperada (en este caso $5 \%=0.05$ )

- $\mathrm{q}=1-\mathrm{p}$ (en este caso $1-0.05=0.95)$

- $\mathrm{d}=$ precisión (en su investigación use un $5 \%$ ). 


$$
\mathrm{n}=\frac{20.000 * 1.96^{2} * 0.05 * 0.95}{0.05^{2}(20.000-1)+1.96^{2} * 0.05 * 0.95}=73
$$

Para el análisis de los datos obtenidos por las encuestas se utilizó el análisis mediante la visualización de datos. Esta metodología permite interpretar de forma gráfica los datos, como lo fue en las encuestas donde se encontraron gráficas de barras, gráficas de torta, así como sus respectivos porcentajes, siendo bastante descriptivos y fáciles de interpretar[34]. En el análisis se logró observar la dispersión que había en una de las preguntas, como lo fue: ¿Dónde publican los músicos sus servicios? Y ¿dónde buscan los clientes a los músicos para solicitar sus servicios? Mostrando la brecha que hay en algo que debería estar directamente relacionado en el mercado.

La visualización de datos, también permitió ver tendencias en los datos obtenidos, como gustos en los géneros, contenido que se deseaba ver, la edad o el género. Esto se dio gracias al planteamiento de las preguntas, las cuales fueron formuladas con múltiple opción, para que no se presentaran subjetividades a la hora de responder, sin embargo, se abrió la posibilidad de anexar más respuestas, según el criterio de los encuestados. Se consideró que la visualización de datos es la metodología más adecuada para el análisis que se requería, pues es sencillo, y los datos está organizados de tal forma que su lectura es fácil de digerir, y nos da cabida para discernir tendencias en las respuestas y poder plantear los requerimientos por los que está trazada la aplicación.

La tendencia en la edad de 18 a 25 años frente a los usuarios que respondieron la encuesta. Esto se debe a que los jóvenes hacen un mayor uso de las redes sociales con una gran proporción a sus labores diarias. Esto influyo en las respuestas de la pregunta 8 ya que la mayoría de músicos tienden a interpretar Rock. Hay que tener en cuenta que los resultados fueron obtenidos gracias a la publicación de la encuesta en grupos de músicos, de diferentes géneros y remitiendo por mensaje a las páginas y perfiles de agrupaciones o solistas, por otra parte, se tomaron los números de WhatsApp y correo de las páginas web o blog de cada grupo para enviar por ese medio la encuesta.
En el levantamiento de información, además del estado del arte, y las encuestas que se realizaron, hubo un aspecto importante a resaltar, y es la experiencia con la que cuenta Oscar López y Nicolas Turga en el ámbito musical y que nos da el criterio para aportar y discernir aspectos que se consideraron necesarios en el desarrollo de la aplicación y las problemáticas que existen, y cómo empezar a resolverlas por medio de la aplicación.

Para recolectar los datos se usaron dos métodos para tal fin. Se usó la auto-observación que se puede definir como: "La técnica donde el observador y la persona observada es la misma persona. La validez de esta técnica depende de la capacidad de desdoblamiento que tenga el investigador para observarse a sí mismo, sin cambiar lo que es su manera "normal" de actuar. Para realizarla, se puede utilizar un registro de anotaciones que luego será interpretado"[35]. Para las anotaciones se tuvieron en cuenta 5 aspectos, los cuales son: participantes, medio, conducta social, frecuencia o duración y problemática. La última se agregó como base para nuestro análisis, pues nuestra intención es proveer soluciones a problemáticas que se identificaron. Las demás se definen así:

- Los participantes, es decir, el tipo de unidad de análisis definida de acuerdo con el estudio; pueden ser obreros, niños, estudiantes, etc.

- El medio, o sea, el ambiente dentro del cual se mueven los participantes, como una fábrica, un jardín infantil o una universidad.

- La conducta social, es el tipo de acción que adelantan los participantes de la situación, como el rendimiento de los obreros, separación de los niños de sus madres en el jardin, participación de los estudiantes universitarios.

- Frecuencia y duración de la situación, si la conducta es técnica o permanente, si se repite esporádicamente, cuándo alcanza su nivel máximo de ocurrencia, etc.; elevación o bajas del rendimiento del trabajo de un obrero en un mes; primeros días de separación de los niños de sus madres; participación politica de los estudiantes universitarios durante el período electoral[35].

Teniendo en cuenta lo anterior se realizaron 3 cuadros donde se describen plenamente estos aspectos; los escenarios que se registran son Transporte Público, Serenatas y Bares-Restaurantes.

Rev. Ingeniería, Matemáticas y Ciencias de la Información Vol. 6 / Núm. 11 / enero - junio de 2019; pág. 
Otro método que se utilizó, es el 'Apprenticing', que se trata de la labor del analista en el rol de usuario aprendiz, realizando las mismas labores que un usuario experimentado; allí es donde, realizando todas las actividades propias del usuario experimentado, se recolectará la mayor cantidad de información que nos permita discernir los aspectos más trascendentales de la labor en cuestión[36].

Este método también es muy útil, pues a pesar de estar realizando un proyecto de ingeniería, también es pertinente ver cómo funcionan las plataformas tecnológicas (previamente citadas en el estado del arte) que hay en el mercado y lo que esto implica en una ciudad como Bogotá. Con el fin de reforzar la metodología, y la pertinencia que tiene en la información que se ha documentado.

En este punto se decidió ver los procesos desde el punto de vista del cliente realizando el proceso de búsqueda y solicitud de servicios para conocer cómo es la interacción en estas páginas y ver cómo manejan la información para discernir aspectos que la aplicación puede aplicar o identificar fallar para así poderlas mejorar. Este método permite determinar las acciones que realizan las personas, este tipo de técnica permite representar estas tareas que las mismas desempeñan. Su principal objetivo es el de describir las tareas que permitan entender el contexto de estas desarrolladas por las personas. Este tipo de técnica requiere de esfuerzos considerables para su desarrollo, ya que esta permite análisis profundos de los procesos que se vayan a observar[36].

Las tareas que realizan las personas (en este caso, clientes y músicos) quedaron descritos en dos formatos que se basan en 2 preguntas para clientes como para músicos, las preguntas para músicos son:

- Realizar una breve descripción de cuál es el medio por el que más lo ubican y cómo es el proceso desde que lo contactan, hasta que se da por terminado el servicio.

- Si se crea una aplicación móvil/web que permita la interacción entre músicos y clientes para solicitar los servicios musicales, qué sugeriría que tuviera y cómo le gustaría que hiciera el proceso dicha aplicación.
Para el caso de los clientes son:

- Realizar una breve descripción de cuál es el medio por el que más busca a los músicos y cómo es el proceso desde que contacta al grupo musical, hasta que se da por terminado el servicio.

- Si se crea una aplicación móvil/web que permita la interacción entre músicos y clientes para solicitar los servicios musicales, qué sugeriría que tuviera y cómo le gustaría que hiciera el proceso dicha aplicación.

Los formatos fueron un ejercicio escrito, teniendo en cuenta dos aspectos, como se denotan en las preguntas. El primero es conocer cómo los músicos manejaban los procesos de divulgación y concretaban los servicios cuando los clientes los requerían. Para los clientes se enfocó averiguando cómo los buscaban y que herramientas usaban.

El segundo aspecto a conocer es qué deseaban ver en la aplicación, y que sugerencias tendrían ante una eventual creación de una aplicación que fuera enfocada en resolver los procesos que ellos describían antes.

El análisis de la información recolectada por este método se encuentra en la siguiente sección de análisis de requerimientos.

\section{RESUltados OBTENIDOS}

\section{A. Encuestas a músicos}

\section{Edad}

73 respuestas

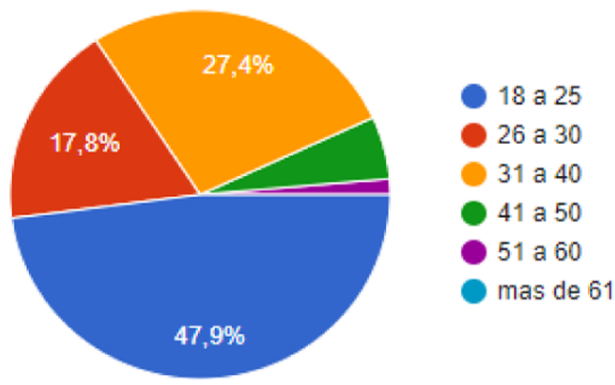

Fig. 1. Respuestas sobre la edad de los músicos encuestados. 
En esta pregunta se puede evidenciar que 47.9 $\%$ de los encuestados (Músicos) está entre la edad de los 18 a los 25 años. Esto nos permitirá desarrollar una aplicación móvil y web orientada a población joven. Sin descartar el otro nicho de mercado, como los son las personas entre los 26 a 40 años.

\section{Género \\ 73 respuestas}

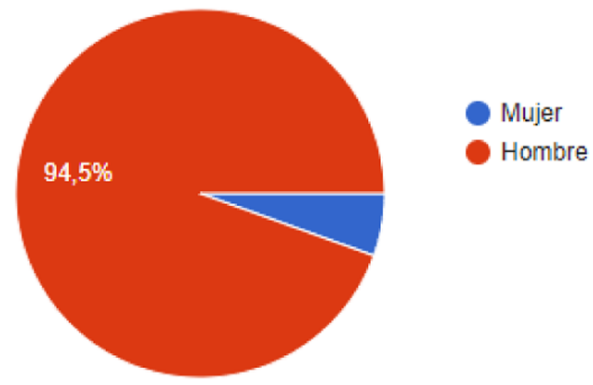

Fig. 2. Respuestas sobre el género de los músicos encuestados.

Es claro destacar que la población encuestada es en su mayoría hombres, con un $94.5 \%$; en el proceso de implementación de la aplicación en el mercado habrá un impacto en primera instancia a la población masculina, desde el entorno gráfico y publicitario de la plataforma.

3. ¿Qué medios utiliza para publicitar su música? Puede elegir varias opciones.

73 respuestas

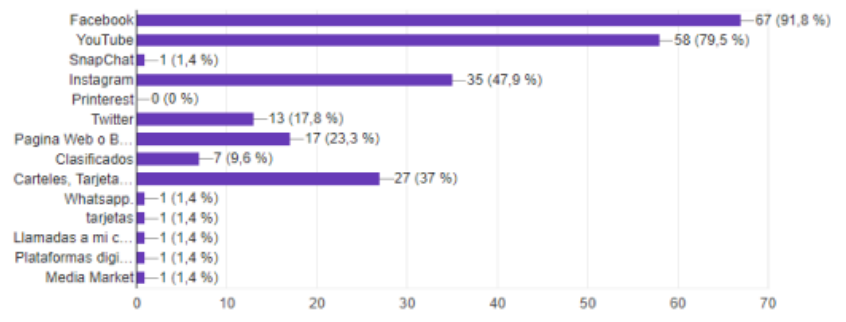

Fig. 3. Respuestas sobre los medios que usa el músico para publicitar su música.

Debido a la preponderancia hacia Facebook, Youtube e Instagram de los encuestados, se abre una puerta hacia qué redes sociales se pueden enlazar con la plataforma, vinculando los perfiles o cuentas en dichas redes, para facilitar el uso de la misma. En ese sentido, la plataforma actuaría como agente publicitario para cada músico o agrupación, mostrando esto a sus clientes para mayor confiabilidad.

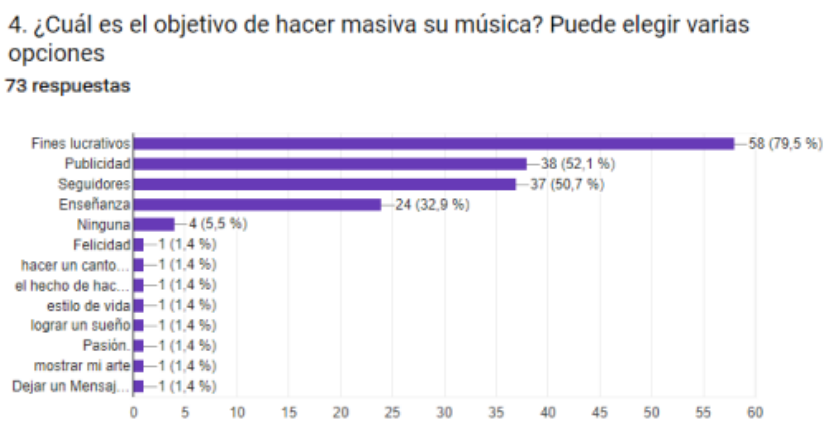

Fig. 4. Respuestas sobre qué motiva a los músicos hacer masiva su música.

Debido a que, para la mayoría de los encuestados, su principal objetivo al hacer música es precisamente comercializar y lucrarse de su trabajo, se puede asegurar que, por medio de la plataforma se debe potencializar un crecimiento en sus ingresos debido a la oferta que potencialmente va a surgir, sin dejar de lado los seguidores o el público que puedan obtener.

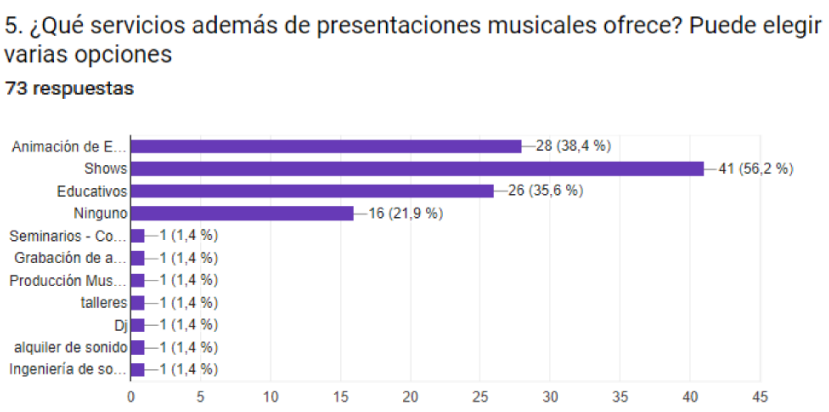

Fig. 5. Respuestas sobre servicios adicionales a presentaciones musicales que ofrecen los músicos.

Esta pregunta indica qué otros intereses tienen los músicos en cuanto a los servicios adicionales que ofrecen; lo que implica que ellos puedan tener un espacio dentro de la aplicación para publicitarlos.

6. ¿Considera que por medio de una aplicación podría aumentar su demanda de clientes?

73 respuestas

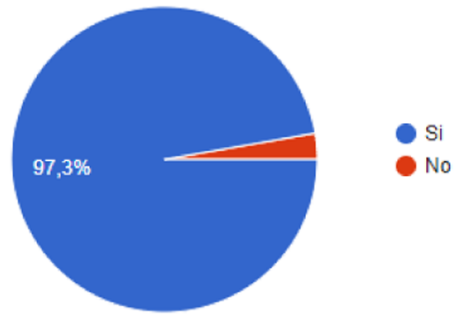

Fig. 6. Respuestas de los músicos, donde consideran si hay o no posibilidad de aumentar clientela, por medio de una aplicación. 
Existe gran expectativa por parte de los músicos, con la aplicación. Debido a que el uso de las aplicaciones se está haciendo de manera masiva.

7. De 10 cotizaciones que le realizan, ¿cuántos servicios se concretar 73 respuestas

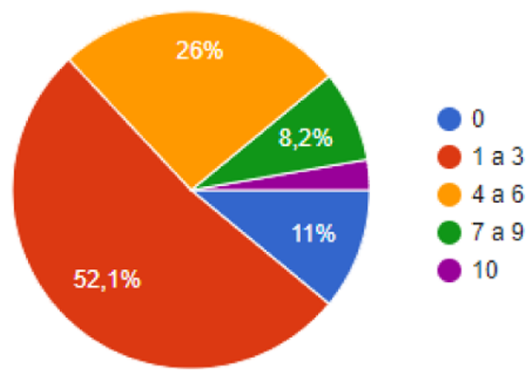

Fig. 7. Respuestas sobre el número de servicios concretados, con relación al número de cotizaciones. ${ }^{7}$

Al observar los valores, la media se ubica entre 1 y 3 cotizaciones que se concretan. Por medio de la plataforma, la idea es aumentar en una prime fase en un $10 \%$ el cierre que una agrupación o músico pueda concretar de sus servicios. Es decir que si un músico hace 10 cotizaciones de la forma tradicional y tan solo concretaba 2 de ellas, se pretenderá entonces que con la aplicación por lo menos le ayude a cerrar una más, es decir 3 negocios.

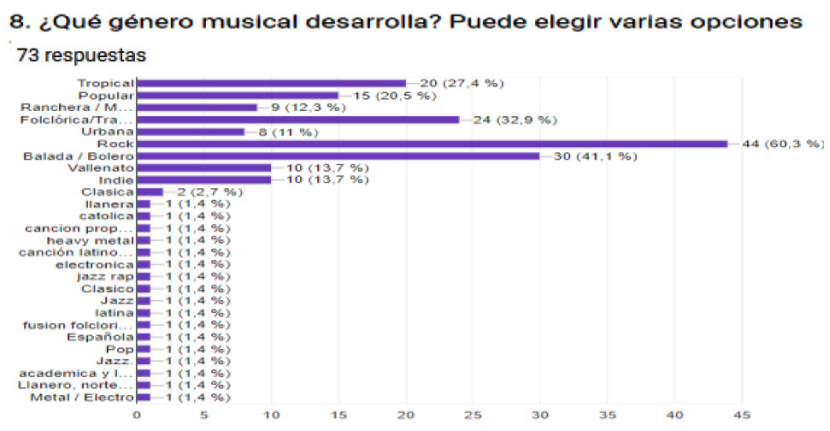

Fig. 8. Respuestas sobre el género musical que desarrollan los músicos.

Esta pregunta brinda información adicional sobre qué géneros son los que más prefiere la población encuestada. Teniendo en cuenta que en la pregunta 12 los músicos dan su opinión frente a cueles creen que son los géneros de mayor demanda en una plataforma. Esta información será especialmente útil para realizar los filtros de las búsquedas y posicionar según géneros musicales.
9. ¿Qué información desearía mostrar a potenciales clientes? Puede elegir varias opciones

73 respuestas

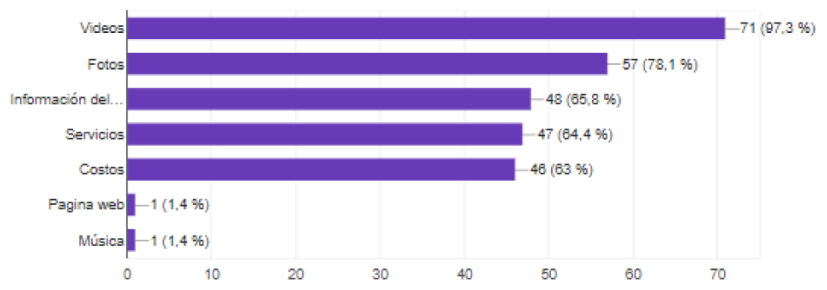

Fig. 9. Respuestas sobre la información que desearían mostrar lo músicos en la aplicación.

Esta pregunta brinda información importante sobre que les interesa a los músicos mostrar desde la plataforma, ya que en su perfil como músico tendrán estas opciones multimedia para hacer publicidad de su trabajo. Se entrarán a evaluar cuantos videos se podrán subir o enlazar a la aplicación, así como las fotos. Se deberá mostrar información de la agrupación o del solista, qué servicios presta y de querer publicar, qué costos tienen dichos servicios.

10. ¿Está de acuerdo que se cree un nuevo mercado laboral para los músicos en la ciudad por medio de una aplicación móvil? 73 respuestas

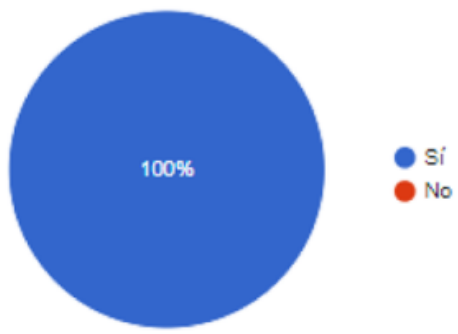

Fig. 10. Respuestas de los músicos sobre la intención de crear un mercado laboral para los músicos por medio de una aplicación.

Es evidente que el uso de las nuevas tecnologías ha logrado impactar en todas las áreas del mercado, como un agente esencial para profesionales de cualquier tipo. De esta manera, el área de la música, no podía pasar desapercibido; se considera necesario el desarrollo de esta aplicación, ya que tendría una buena acogida, y se prestaría para que otras expresiones artísticas tuvieran un mercado en el mundo digital. 
11. Desde su perspectiva, ¿qué tan bueno o tan malo es una iniciativa como esta?

73 respuestas

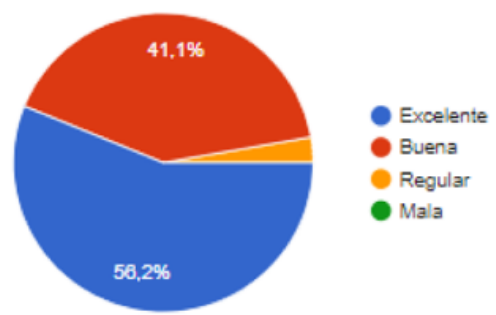

Fig. 11. Respuestas de los músicos sobre qué tan buena o mala es la iniciativa de la aplicación.

En la anterior escala referente a como los músicos calificarían esta iniciativa se evidencia que el $97.3 \%$ de los encuestados la califican de buena manera, esto justifica el fin de continuar con el desarrollo de la plataforma.

12. ¿Cuáles géneros considera que tendrian más demanda dentro de la aplicación? Puede elegir varias opciones

73 respuestas

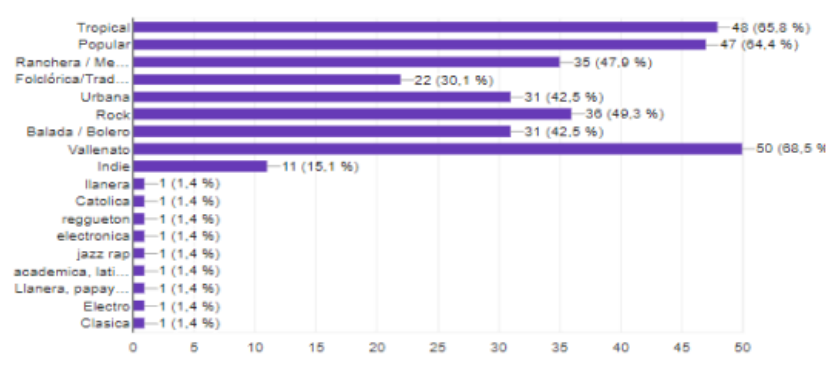

Fig. 12. Respuestas sobre el género musical que tendría más demanda dentro de la aplicación.

Independientemente del género que desarrollan los músicos que respondieron esta encuesta, se muestra desde la perspectiva de su profesión cuales creen ellos que serán los géneros más solicitados. Con porcentajes que oscilan del $47 \%$ al 50\% (Popular, tropical, vallenato) son los géneros que tienen una tendencia a ser de mayor demanda para cualquier ocasión por el contexto cultural en el que se vive

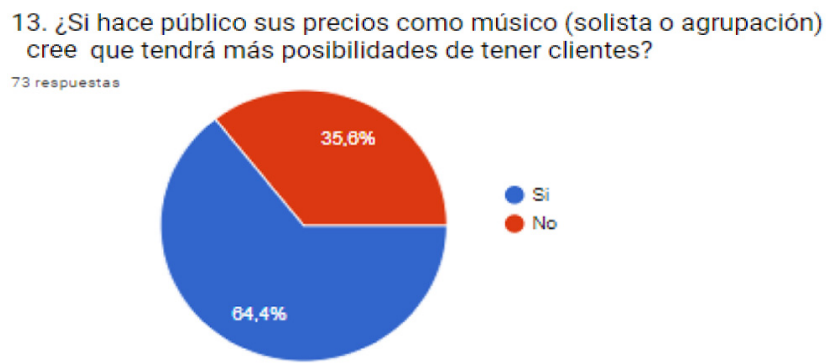

Fig. 13. Respuestas sobre la posibilidad de tener más clientes si se muestran los precios de los servicios.
Analizando los resultados obtenidos es claro que existe un porcentaje considerable de usuarios que no publicarían sus precios a la hora de ofrecer sus servicios. Esto indica que, la plataforma si debe contener un espacio para publicar precios, pero estará a disposición del músico hacerlo.

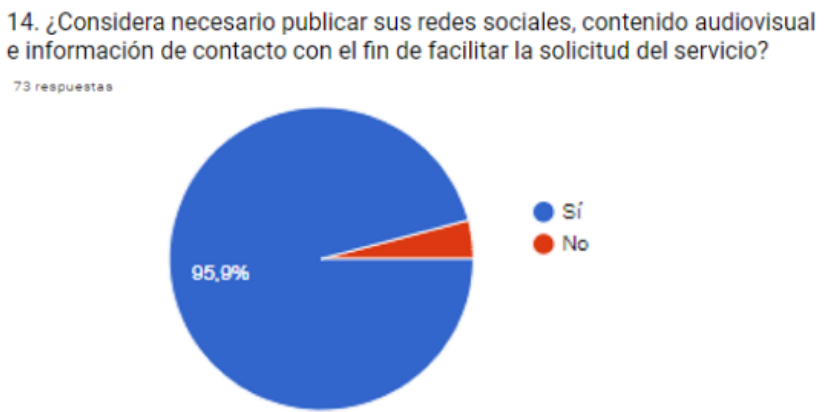

Fig. 14. Respuestas sobre la posibilidad de publicar redes sociales, contenido audiovisual e información de contacto para facilitar la solicitud del servicio.

Los músicos encuestados si están de acuerdo en que se publique información sobre ellos, teniendo en cuenta las respuestas a las preguntas 3 y 9 , es preciso afirmar que la plataforma contará con espacios para publicar; redes sociales como: Facebook, Youtube e Instagram (medios que utilizan con mayor frecuencia) además de videos, fotos, productos y servicios.

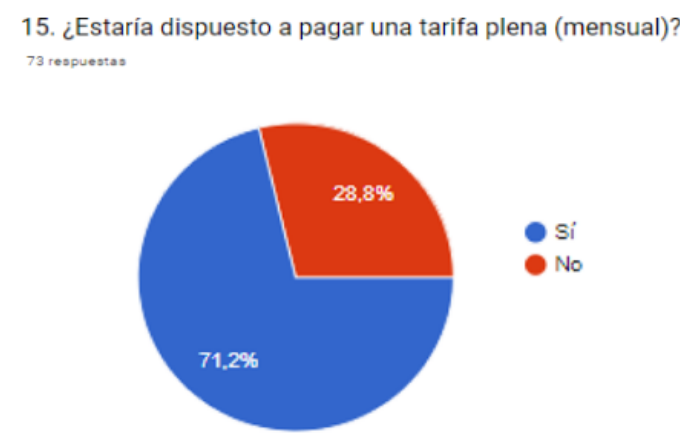

Fig. 15. Respuestas sobre la disposición de los músicos a pagar una tarifa para el uso de la aplicación.

A pesar de ser una gran propuesta, se evidencia una buena aceptación a la hora de cobrar por los servicios que ofrezca la aplicación; sin embargo, de forma preliminar por contar con las funcionalidades básicas, será gratis. Luego se deberá pensar por cuáles servicios "Premium" se podrían cobrar para obtener mejores beneficios para los músicos. 
16. Si está dispuesto a pagar la tarifa plena (mensual) ¿en qué intervalo oscilaria el precio a pagar? Nota: Recuerde que si contestó NO a la pregunta anterior en esta deberá seleccionar la opción No aplica y si selecciono SI a pregunta anterior deberá elegir una de las opciones menos la opción No aplica.

73 respuestas

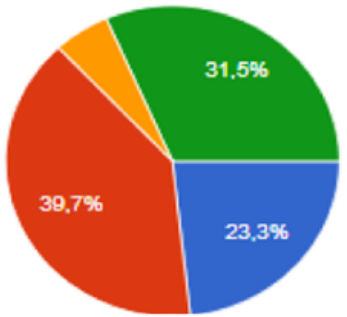

Fig. 16. Respuestas sobre la tarifa que estarían dispuestos a pagar los músicos, en caso de estar de acuerdo.

De acuerdo a la pregunta anterior, los valores dispuestos a pagar por los músicos oscilarían entre los 7.000 y los 25.000 pesos.

\section{B. Encuestas a los clientes}

El siguiente análisis corresponde a una encuesta realizada desde el 17 de junio de 2017 hasta el 27 de junio de 2017, donde se pregunta a las personas sobre su edad, género y diferentes aspectos a tener en cuenta sobre el mercado de músicos en Bogotá, cada cuánto lo utilizan, y qué posibilidades se tienen para el desarrollo de una aplicación móvil.

Allí se pudo encontrar diferentes tendencias, a continuación, serán explicadas con cada pregunta. Las personas que respondieron la encuesta fueron contactadas por medio de redes sociales como Facebook y WhatsApp; amigos, familiares y personas sin ningún vínculo personal o familiar. La encuesta fue divulgada por el grupo y otros conocidos que ayudaron a compartirla entre sus contactos más cercanos; esta se realizó con la herramienta Google Formularios, solo se hizo por medio virtual obteniendo así 109 personas encuestadas. A continuación, el análisis de cada pregunta.

\section{Edad 109 respuestas}

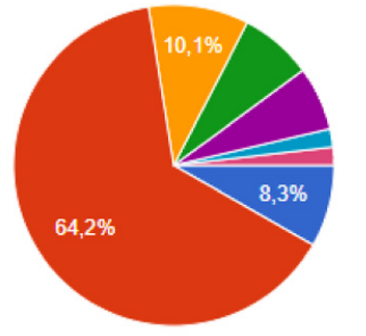

13 a 17 26 a 30 31 a 40 - 40 a 51 51 a 60 mas de 61

Fig. 17. Respuestas sobre la edad de los clientes encuestados
En esta pregunta se puede evidenciar que 64.2 $\%$ de los encuestados (clientes) está entre la edad de los 18 a los 25 años. Esto nos permitirá desarrollar una aplicación móvil y web orientada a población joven.

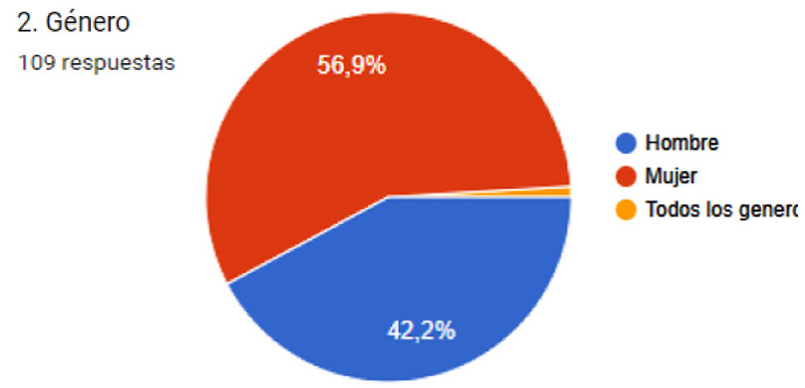

Fig. 18. Respuestas sobre el género de los clientes encuestados.

Observando los porcentajes, la aplicación quedaría disponible en casi la misma proporción para hombres que para mujeres, donde las mujeres serían las que tenderían a solicitar más los servicios musicales de acuerdo a la gráfica.

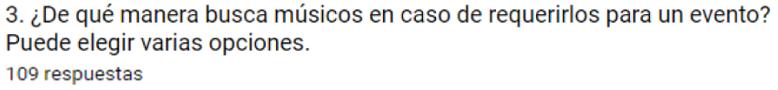

Fig. 19. Respuestas de los clientes sobre la manera que buscan músicos para un evento.

En esta pregunta se observa que a pesar de los avances en cuanto a publicidad y la comunicación, muchos de los trabajos pululan en el mercado gracias al voz a voz. Lo que obliga a recurrir a las calles y acercarnos a los sitios donde los músicos frecuentan a la espera de un cliente, para así masificar la aplicación, con el recurso de voz a voz, poder garantizar más músicos que usen la plataforma. Gracias a la información obtenida se tienen que ofrecer los medios más utilizados al método tradicional de búsqueda de músicos desde la aplicación, bien sea de forma publicitaria, alojamiento de información, enlace a redes sociales o comentarios de los clientes como vínculos de recomendación para otros clientes interesados. 
4. ¿Cuánto tiempo le toma buscar, contactar y concretar la solicitud de un músico?

109 respuestas

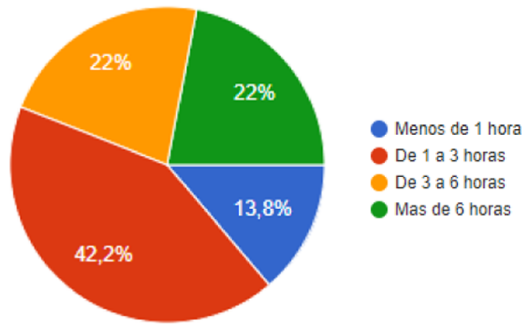

Fig. 20. Respuestas de los clientes sobre el tiempo que requiere para buscar, contactar y concretar una solicitud a un músico.

Se encuentra una tendencia de 1 a 5 horas en poder buscar, contratar y concretar una solicitud. Lo que se pretende mejorar con la aplicación, pues se buscará que se hagan los vínculos de una manera más rápida, sin tener que acudir a clasificados o desplazamientos dentro de la ciudad disminuyendo así el tiempo considerablemente.
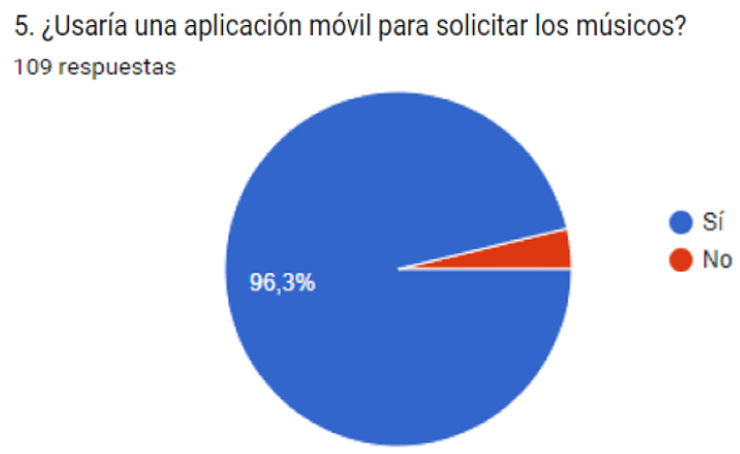

Fig. 21. Respuestas de los clientes sobre utilizar o no una aplicación para solicitar músicos.

La gráfica de los resultados a esta pregunta demuestra que entre los clientes habría gran aceptación para el uso de la misma. Lo que da más confiabilidad a la hora de desarrollarla.

6. ¿Considera que ahorraría tiempo y dinero con el uso de la aplicación? 109 respuestas

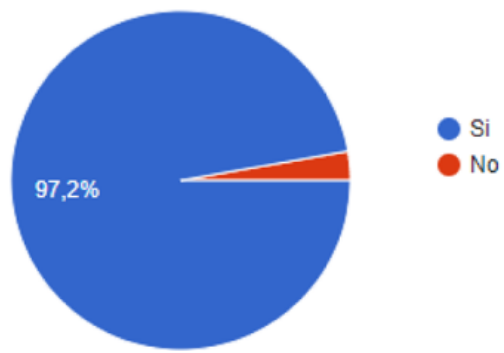

Fig. 22. Respuestas de los clientes sobre el ahorro de tiempo y dinero con el uso de la aplicación.
La mayoría de los encuestados aboga por el ahorro de tiempo y dinero, lo que permite evidenciar una factibilidad en el uso por parte de los clientes a la hora de ponerla en marcha.

7. ¿Qué información le gustaría ver a la hora de solicitar de manera confiable a un músico? Puede elegir varias opciones.

109 respuestas

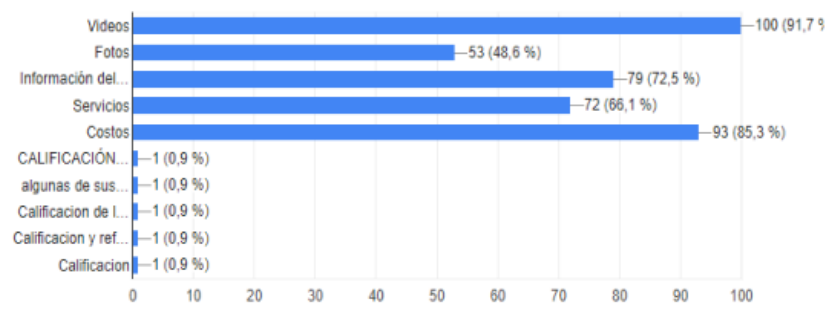

Fig. 23. Respuestas de los clientes, sobre la información que le gustaría ver a la hora de solicitar un músico.

En la gráfica se puede evidenciar que los clientes prefieren ver videos, y los costos que podrían acarrear con la presentación del músico, por encima de otros. Aunque también agregan que calificación tengan estos los músicos. Esto da el aval para hacer un sistema para calificar y medir la satisfacción del servicio prestado.

8. ¿Estaría dispuesto a pagar una tarifa plena (mensual)? 109 respuestas

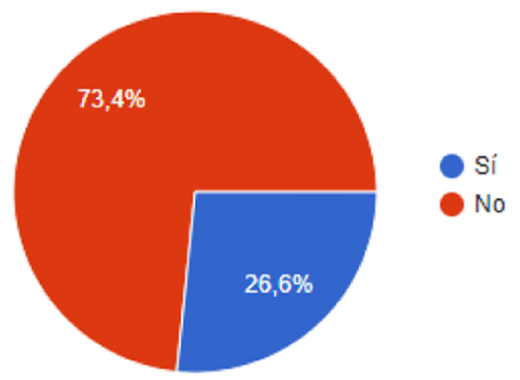

Fig. 24. Respuestas de los clientes sobre si estarían de acuerdo con pagar una tarifa plena.

Los clientes por el uso de la aplicación no estarían dispuestos a pagar en su mayoría, por esta razón quedaría descartada la posibilidad de cobrar inicialmente por el uso de la aplicación. 
9. Si está dispuesto a pagar la tarifa plena (mensual) ¿en qué intervalo oscilaría el precio a pagar? Nota: Recuerde que si contestó NO a la pregunta anterior en esta deberá seleccionar la opción No aplica, y si selecciono SI a la pregunta anterior deberá elegir una de las opciones menos la opción No aplica.

109 respuestas

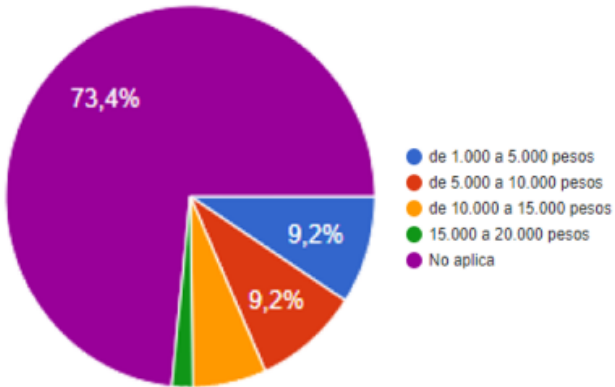

Fig. 25. Respuestas de los clientes sobre el precio de la tarifa que estarían dispuesto a pagar.

Teniendo en cuenta la respuesta de la pregunta anterior se sabe que los clientes no estarían dispuestos a pagar, pero igual si observaron algunos de los que pagarían estarían en un valor medio de 1.000 a 10.000 pesos.

10. ¿Qué tipo de actividad u ocupación desarrolla?Puede elegir varias opciones.

109 respuestas

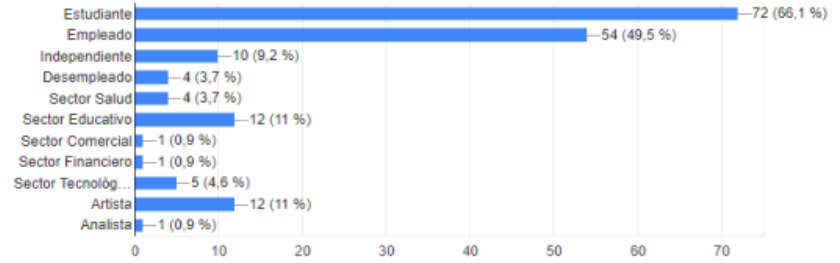

Fig. 26. Respuestas de los clientes sobre las actividades que realizan

La información obtenida referente a las ocupaciones de los clientes nos será útil para analizar en qué sector o tipo de ocupación impactaría con mayor fuerza la implementación de la aplicación. Por ejemplo, es importante tener en cuenta que los estudiantes por el uso de las tecnologías estarán más actualizados referente al uso de las nuevas tecnologías.

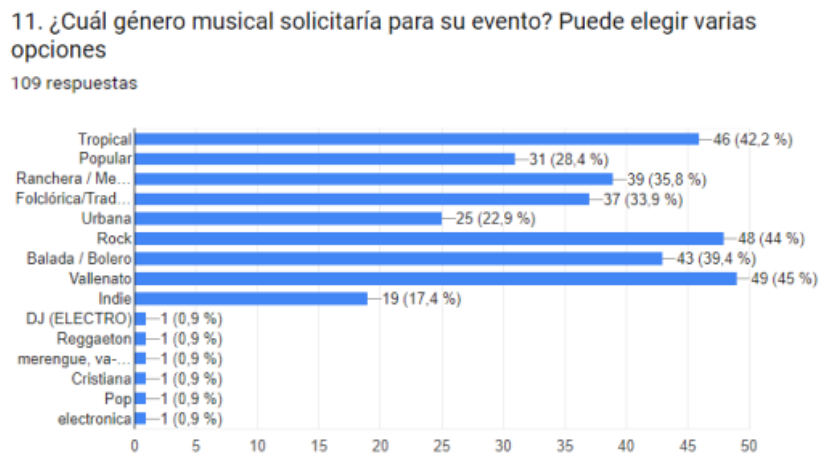

Fig. 27. Respuestas de los clientes sobre los géneros de preferencia para solicitar un músico.
Esta pregunta es importante ya que ofrece un listado de la importancia que le dan las personas a los distintos géneros. Se encuentra que por tradición los géneros más solicitados están basados en la cultura Colombiana, como el vallenato, el rock, la ranchera, la música popular y tropical. Teniendo en cuenta esto se sabe que la plataforma tendrá que ser promocionada en los sitios donde más frecuenten músicos de estos géneros.

\section{2. ¿Cuantas veces al año solicita un servicio musical?}

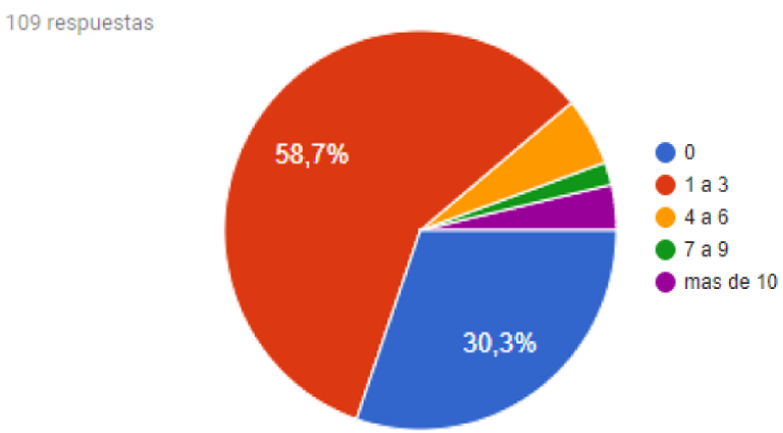

Fig. 28. Respuestas de los clientes sobre cuántas veces al año, solicita un servicio musical.

La moda está de 1 a 3 servicios solicitados en un año, esto indica que las personas si estarían utilizando la plataforma por que existe una demanda para este tipo de servicios en la ciudad origen del estudio (Bogotá).

\section{DisEÑO}

El diseño de la aplicación se hizo por medio de Mockups, donde se evaluaron las iteraciones posibles que iba a caracterizar la funcionalidad de MusicApp. Cuenta con 3 vistas en total: la vista web desde computador (navegadores web), la vista web desde el celular (responsiva), y la vista móvil (nativa) que es para teléfonos inteligentes.

El color que se utilizó para la aplicación, como para el logo es el azul, y tonalidades derivadas del mismo, ya que al azul se lo asocia con la inteligencia y las emociones profundas. El color azul simboliza la sabiduría, la fidelidad y la verdad[37]. Y lo más importante, no fatiga los ojos en grandes extensiones. Otra razón importante es que muchas marcas de reconocimiento mundial como Facebook, Twitter, Pepsi, HP, LinkedIn, Ford, Skype tienen tonalidades azules en sus diseños; en ese sentido nos brinda más confianza escoger el azul como color característico. 
La elección del nombre de la aplicación se hizo por unanimidad en el grupo de trabajo, teniendo en cuenta que es original y al momento de la redacción de este trabajo no existe ninguna aplicación con este nombre. La elección del logo se hizo gracias a una encuesta realizada por la red social Facebook, poniendo 3 opciones (cada integrante hizo una propuesta) y se sometió a votación. El diseño del logo ganador se compone por la inicial del nombre de la aplicación, esta se compone por la unión de dos figuras musicales, como los son las corcheas, en la parte posterior se muestra un símbolo que representa la ubicación, pues el prototipo está desarrollado para que la comunicación y la relación entre clientes y músicos sea en tiempo real. Esto anterior haciendo apología a la inmediatez que el prototipo puede brindar. Como se evidencia en la Fig. 29. y Fig. 30.

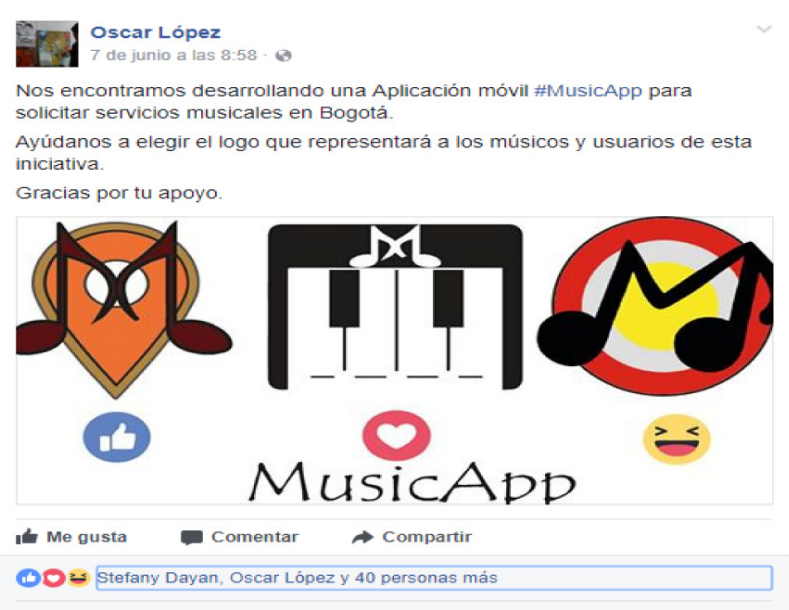

Fig. 29. Votación 1 para elección de Logo.

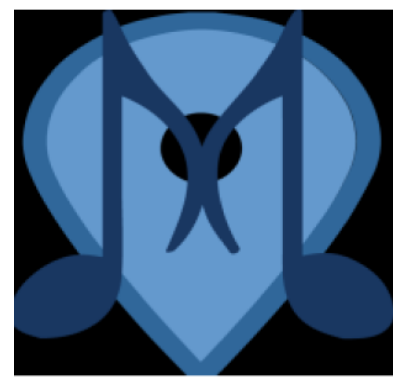

Fig. 30. Logo final.

Hubo 47 reacciones, donde el logo 1 de izquierda a derecha obtuvo 24 'me gusta', el logo 2 obtuvo 15 'me encanta', y el logo 3 obtuvo 8 'me divierte'. El color del logo cambia debido a las razones anteriormente expuestas sobre la psicología de color, como se ve en la Fig. 31.

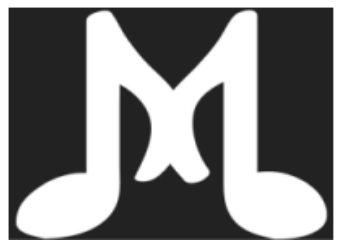

Fig. 31. Logo secundario

A demás de esto, también se derivó del logo principal, uno secundario, que se usa como botón para las notificaciones, y como estético cuando se agenda un servicio, y cuando el músico acepta o cancela dicha solicitud. Como se puede ver a continuación.

\section{A. Mockups}

A continuación, se muestran algunos de los Mockups que se realizaron, enfatizando en las funciones más importantes que tiene la aplicación, como los son los registros, el login, vista perfil del músico, agendar servicio, aceptar o cancelar servicio, notificaciones y solicitudes. Figs. 32 a 35.
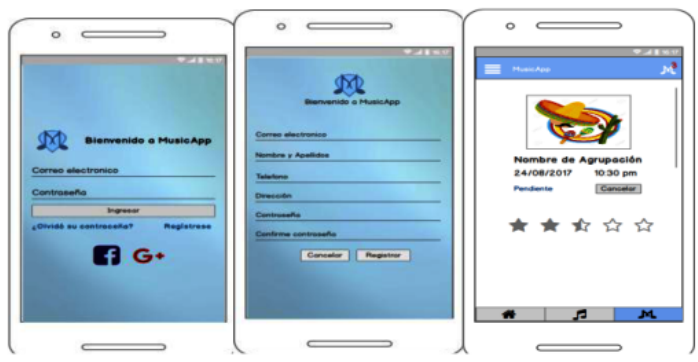

Fig. 32. Formulario de Logln, Registro y Solicitud Pendiente de la vista móvil.

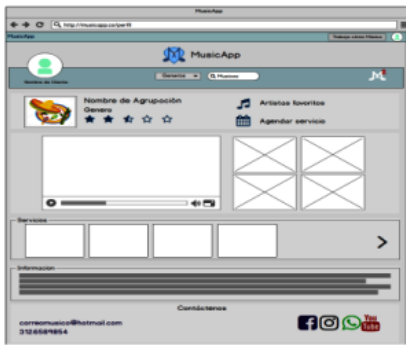

Fig. 33. Vista perfil músico [de izquierda a derecha] móvil y web.
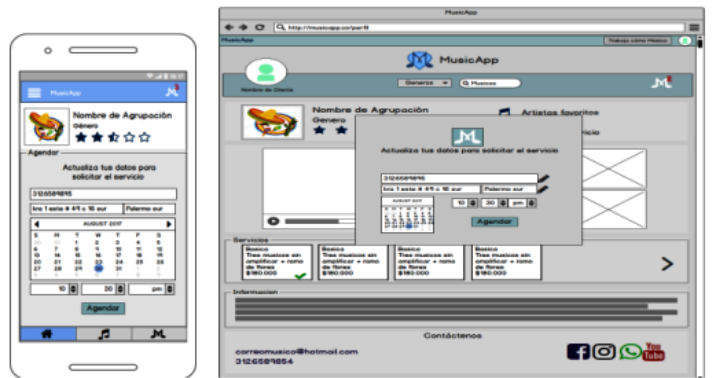

Fig. 34. Agendar servicio [de izquierda a derecha] móvil y web. 

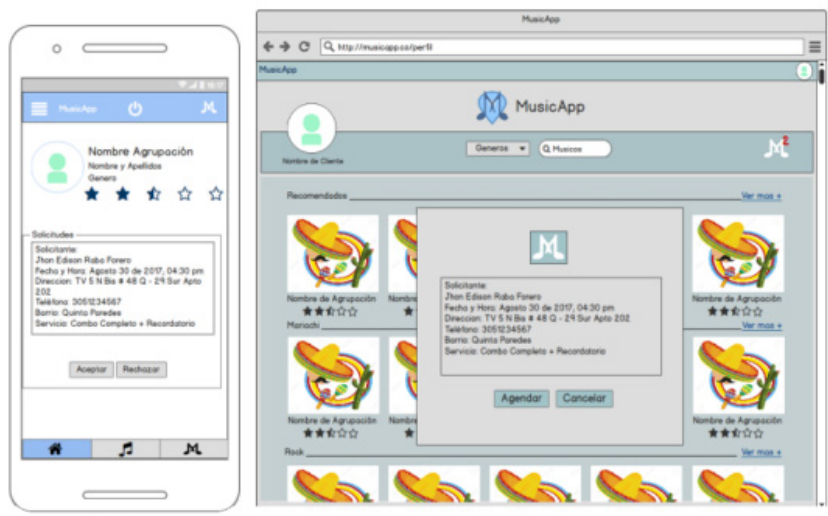

Fig. 35. Aceptar o Cancelar Servicio (de izquierda a derecha) móvil y web.

\section{Desarrollo}

MusicApp se desarrolló bajo el patrón MVC para tener un control de los datos, de tal manera que el controlador pueda ser usado por todas las vistas que se diseñaron, para este caso, web y móvil, y la interacción entre estas fueran independientes la una de la otra.

\section{A. WEB}

Modelo: El modelo está desarrollado sobre JavaScript, basado en AJAX, los datos se envían por método POST, y se utilizó el objeto JSON para encriptar y desencriptar la información. Las iteraciones de la aplicación deben ser en tiempo real, por lo cual el módulo de notificaciones se recarga cada segundo, así permitiendo una conectividad entre los usuarios ipso facto. De acuerdo con lo anterior la aplicación se ejecuta de manera asíncrona, permitiendo cambios y optimizando los servicios sin que el usuario tenga que recargar la aplicación.

Vista: La vista está desarrollada por medio de HTML y CSS, haciendo uso del framework Bootstrap. Se crearon de manera dinámica elementos dentro de la aplicación (DOM), permitiendo modificaciones en la presentación de la vista, y cómo se quiere organizar. Generando elementos que agrupan a otros, y jerarquizando su funcionalidad.

Controlador: Los controladores están desarrollados en PHP, son los que permiten la conexión entre el modelo, y la base de datos. Permiten en- viar datos, garantizando su almacenamiento, y halando la información requerida desde la programación hecha. Allí también se encriptan las contraseñas por medio de MD5. En general en el controlador se realiza todo el CRUD, para el funcionamiento de la aplicación.

\section{1) Vista WEB. Figs. 36 a 41.}

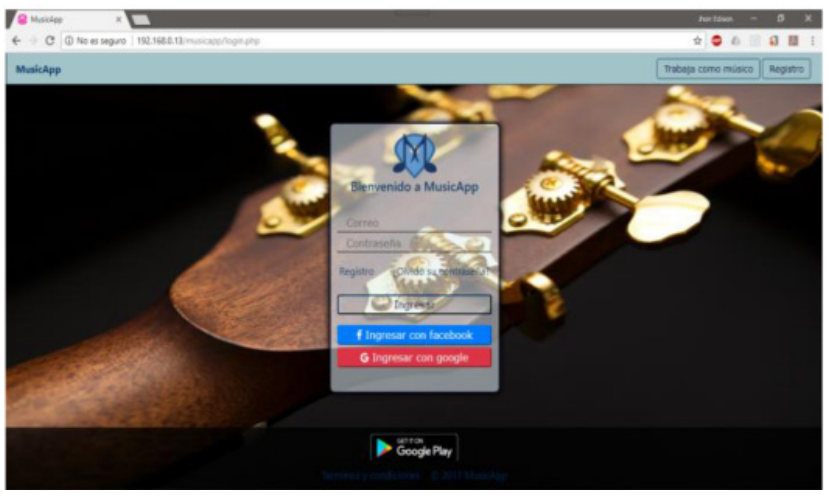

Fig. 36. Vista del Formulario de Inicio de Sesión Web.

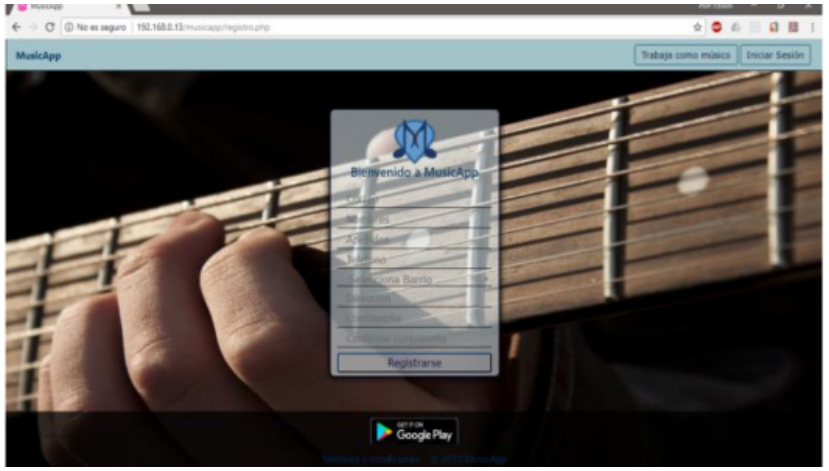

Fig. 37. Vista del Formulario de Cliente Web.

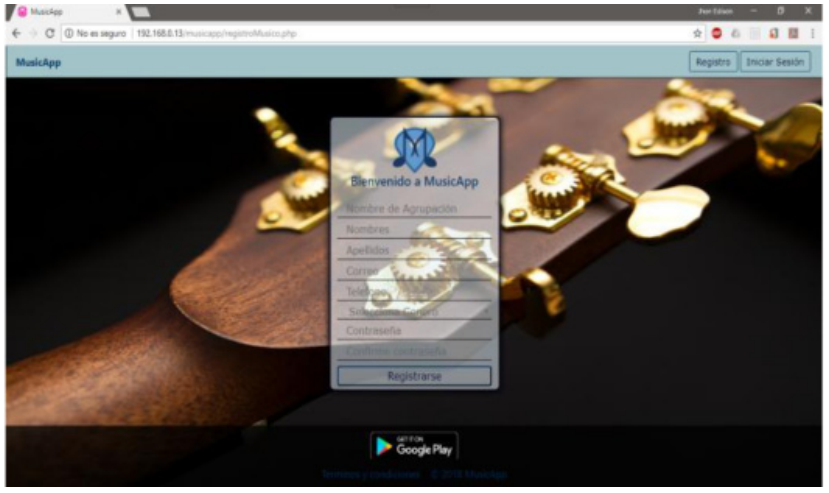

Fig. 38. Vista del Formulario de Músico Web. 


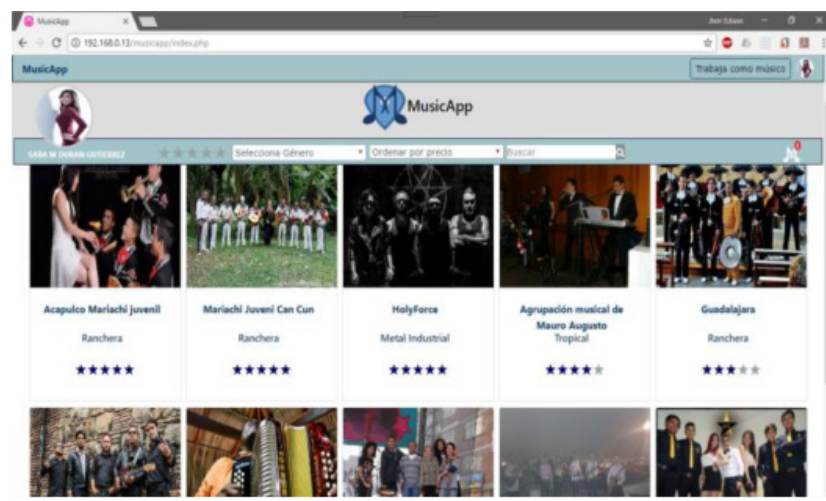

Fig. 39. Vista del Home Web.

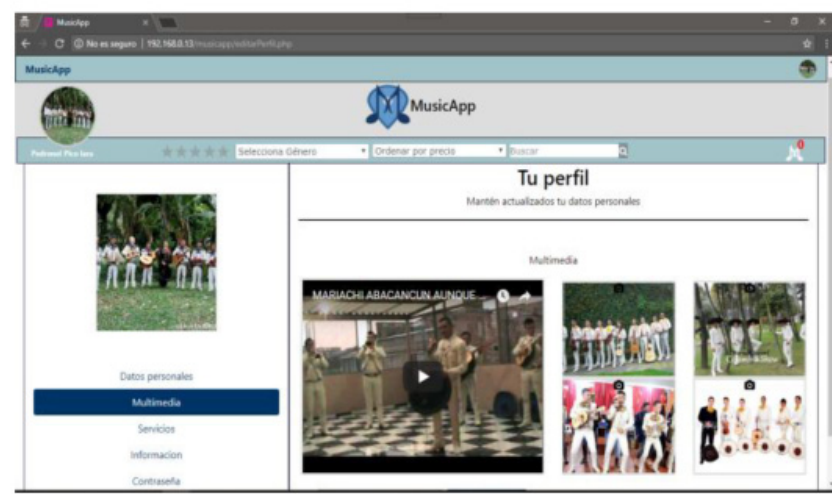

Fig. 40. Vista Multimedia Web.

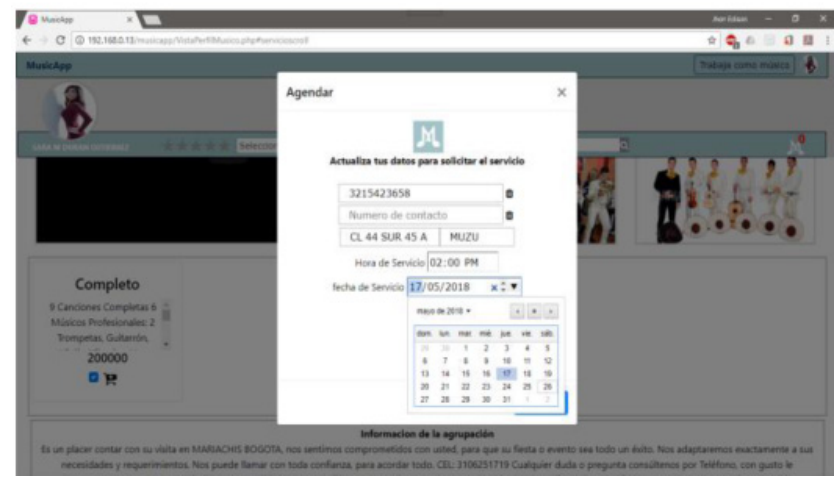

Fig. 41. Vista Agendar Servicio Web.

\section{B. Móvil}

Modelo: El modelo está desarrollado sobre Java, basado en AJAX, los datos se envían por método POST, y se utilizó el objeto JSON para encriptar y desencriptar la información. Las iteraciones de la aplicación deben ser en tiempo real, por lo cual el módulo de notificaciones se recarga cada segundo, así permitiendo una conectividad entre los usuarios ipso facto. De acuerdo con lo anterior la aplicación se ejecuta de manera asíncrona, permitiendo cambios y optimizando los servicios sin que el usuario tenga que recargar la aplicación.
Vista: La vista se realizó por medio de Java con la plataforma Android Studio. Se utilizaron Fragments (Fragmentos) para hacer la mayoría de las vistas, con el fin de hacer más liviana la aplicación, que si toda la App se hubiera desarrollado con Activity.

Controlador: Los controladores están desarrollados en PHP, son los que permiten la conexión entre el modelo, y la base de datos. Permiten enviar datos, garantizando su almacenamiento, y halando la información requerida desde la programación hecha. Allí también se encriptan las contraseñas por medio de MD5. En general en el controlador se realiza todo el CRUD, para el funcionamiento de la aplicación.

\section{1) Vista movil. Figs. 42 a 44.}
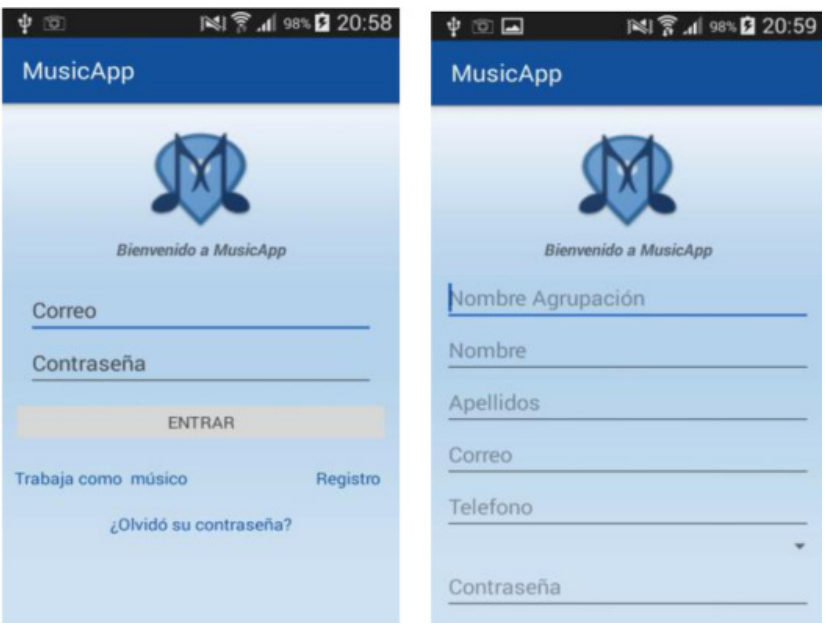

Fig. 42. Vista Inicio de Sesión y Formulario Músico Móvil.
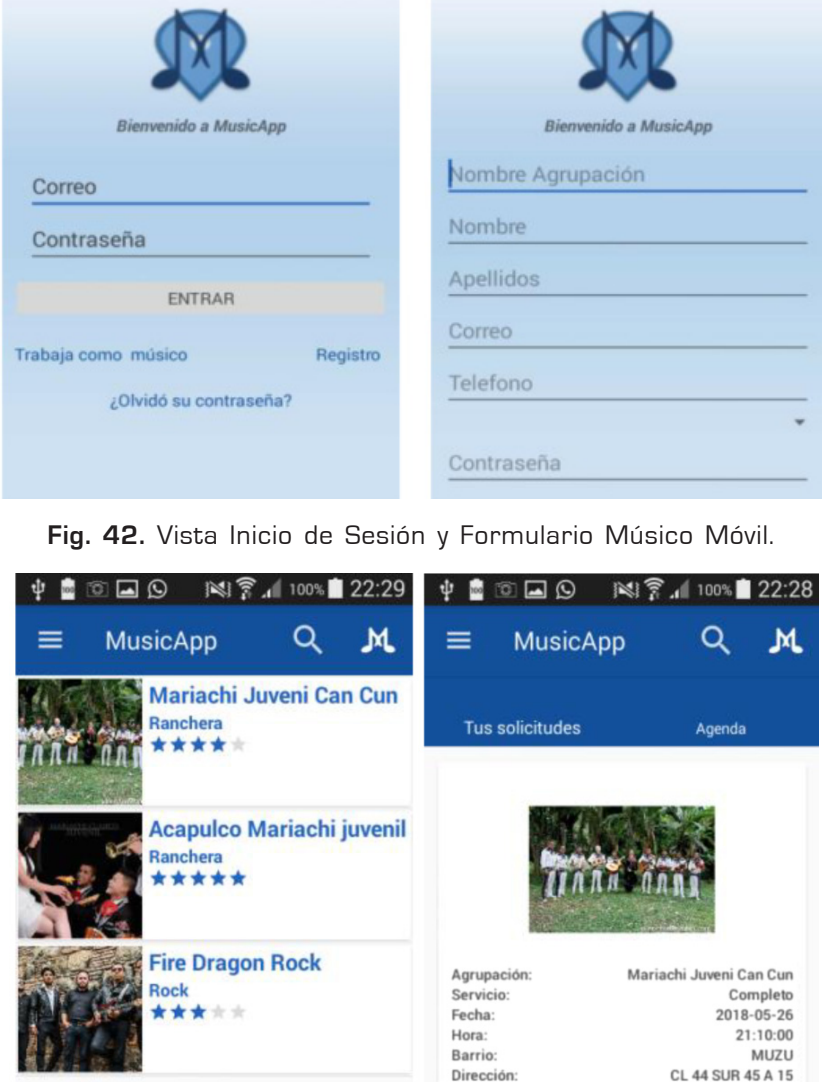

Correo

Telefono

Contraseña
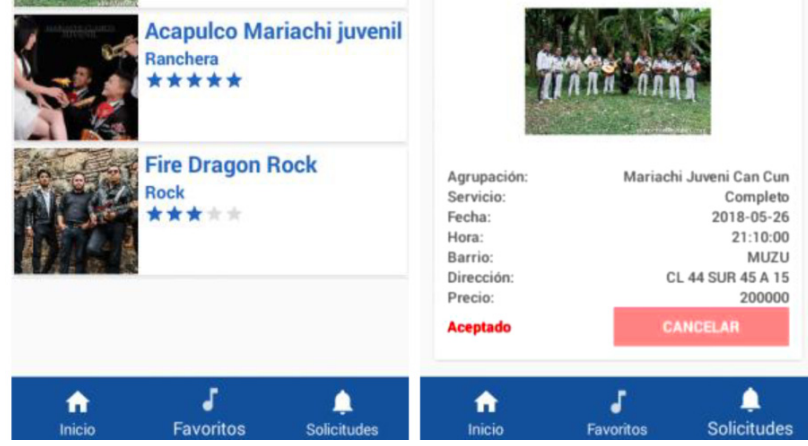

Fig. 43. Vista Home Móvil y Solicitudes Móvil. 

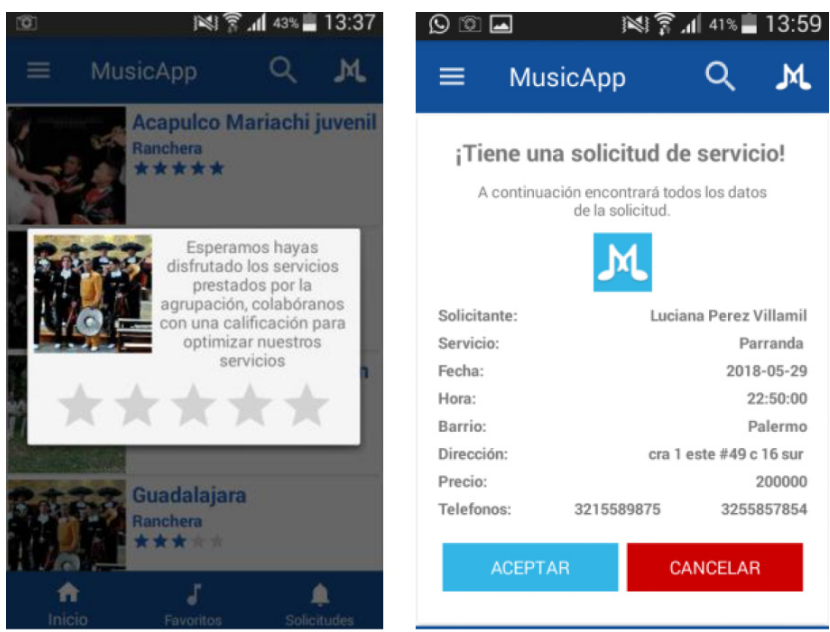

Fig. 44. Calificar grupo y Aceptar o Cancelar Servicio.

\section{Conclusiones}

Se pudo constatar mediante el levantamiento de información la necesidad de diseñar y desarrollar una aplicación que se convierta en un canal de contacto entre los músicos de la ciudad de Bogotá y los clientes que residen en dicha ciudad. Las encuestas arrojaron datos importantes para la construcción tanto de las vistas web, como de las vistas para un dispositivo móvil, respondiendo a los requisitos que se deseaban ver de los músicos (en caso de los clientes), como los músicos, y lo que deseaban publicar para aumentar su demanda de clientes. Se encontró una dispersión entre el modo de búsqueda y el modo de hacer publicidad, pues los clientes usan medios más como el voz a voz, desplazarse a sitios donde haya un gran cúmulo de músicos, carteles y tarjetas. Contrario a esto, los músicos encuestados usan las redes sociales como Facebook, Youtube e Instagram para publicitar su música y servicios. Un componente adicional que se encontró en el camino, es que por medio de WhatsApp es donde más se concretan servicios. Para los músicos es una aplicación valiosa, pues hay relación directa con los clientes ultimando detalles logísticos de una determinada solicitud.

Se logró a partir del análisis de las encuestas plantear los requerimientos necesarios para que la aplicación tuviera la funcionalidad que estaba pensada. De esta manera se concluyó qué requerimientos eran funcionales, y cuáles no, permitiendo una jerarquía en qué módulo se debían programar al inicio, y de ese modo el desarrollo fuera encaminado primero a revolver los requerimientos funcionales. Así, fue fundamental la realización de un modelo entidad relación que nos mostrara cómo se iban a manejar los datos, qué tipo de variables se iban a usar, qué extensión, y las relaciones entre los datos. De este modo fue satisfactorio modelar y ver en ejecución la base de datos, viendo las interacciones, y las restricciones que tendría en caso de querer borrar o alterar la información allí, pues las tablas dependen directamente de otra, y se asegura que la información está sujeta a datos almacenados en otra tabla.

En cuanto al diseño, que en un principio se hizo por medio de MockUp, contemplando unos mínimos y máximos para que la aplicación fuera fácil de usar, en el camino, este fue teniendo cambios que requerían un enfoque diferente para que la aplicación se adecuara a las necesidades de los potenciales usuarios. El diseño en su etapa de prototipo se realizó de la forma más amigable posible, usando la herramienta Balsamiq, sin saturación de colores en su presentación, y organizado de tal manera, que no sea confusa la usabilidad al interior de la aplicación. Se requieren mejoras de forma, para que las iteraciones sean más rápidas, estas se lograrán en el tiempo y validaciones con distintos grupos de usuario, pues la ingeniería es un constante avance, y adaptación a nuevos paradigmas académicos y técnicos, que obligarán a cambiar algunos parámetros y nuevas formas de entender el desarrollo web como móvil, que es donde se decidió incursionar.

Este desarrollo permitió el aprendizaje de nuevos conceptos y el refuerzo de algunos que se habían adquirido durante algunas asignaturas del pregrado. Hacer uso de tecnologías como AJAX no permitió ver desde otra óptica cómo se puede organizar los datos entre la base de datos y la interfaz gráfica. Se eligieron los lenguajes de programación que se lograrían integrar de manera más práctica, llegando a estructurar cada una de las secciones (web y móvil) para que tuvieran los mismos controladores. Cabe resaltar que el desarrollo se truncó en algunas etapas por aspectos como el tiempo, los recursos y discrepancias en cómo se debían abordar los problemas o aciertos dentro del proceso. Al final hubo acuerdos sobre cómo se debían enlazar cada uno de los elementos de la programación, de tal manera que exis- 
tiera un entendimiento total de lo que se estaba desarrollando.

La implementación lograda permitió ver en qué se debe mejorar, para así hacer una transición desde un prototipo a un producto más robusto, con todas las garantías técnicas que se requieran. Sin embargo se evidenció la funcionalidad de la aplicación, donde se ve la conexión entre los clientes y los músicos, además de los módulos que están dentro de esta. Esta conexión estará dada por la la inmediatez, que se presenta como la apuesta de valor desde esta aplicación, y la proyección va encaminada a reducir los tiempos y costos de desplazamiento, pues los encuestados asintieron en que el tiempo se reduciría con el uso de la aplicación; en ese sentido MusicApp tiene alta expectativa para mejorar de manera sustancial a un gremio, que si bien tiene rentabilidad cuando se llega al reconocimiento local, nacional o internacional, este proceso no es fácil o inmediato. Adicional hacer uso de las herramientas tecnológicas, aprovechando su auge es importante y además necesario para un país y una sociedad que quiere tener más equidad, brindando más y mejores oportunidades laborales o aumentando los ingresos en función de una economía cada día más competitiva, propendiendo por ser una puerta para mejorar la calidad de vida al incluir a la ciudadanía en una apuesta de promoción en nuevos mercados digitales.

Uno de los aspectos más fundamentales, es que la implementación de un producto debe estar sujeta a un esquema de seguridad donde los usuarios estén tranquilos de que sus datos están protegidos, y que, a pesar de eventos adversos, hay un control sobre la información almacenada por ellos. Otro aspecto fundamental, es que la idea puede ser llevaba a cabo a nivel nacional; claro, con todas las medidas que se requieran, pero es totalmente aplicable al contexto nacional, pues el gremio sufre de los mismos problemas, independiente de la ciudad en la que se realizó el presente estudio-desarrollo. Por otro lado, existe la necesidad de adquirir un hosting que brinde y garantice acuerdos de niveles de servicio (ANS) otorgando calidad al servicio que se pretende prestar.

Los aspectos técnicos quedaron explícitamente descritos en todo el cuerpo del trabajo, en ese sentido, es importante resaltar que los procesos aca- démicos, y en particular, el trabajar sobre una monografía permiten que las competencias que se buscan cultivar desde primer semestre se vean reflejadas y condensadas sobre una idea que expresa la manera como el grupo ve el mundo, y que el trabajo en equipo no solo es fundamental sino obligatorio, en cualquier aspecto de la vida, ya sea laboral, familiar o personal. La experiencia y conocimientos adquiridos en un ambiente académico está sujeta si y solo sí, a que, como estudiantes y futuros profesionales, se logre estar dispuestos a crear conocimiento, productos o servicios. Lo demás que se requiera se irá adhiriendo en la búsqueda de una respuesta a los planteamientos que se desean llevar a cabo, sin dejar de lado, el acompañamiento de la Universidad en estos procesos como agente conductor entre cada etapa.

\section{REFERENCIAS}

[1] Redacción EL TIEMPO, BOGOTA. Las desventajas de ser músico en Bogotá. Recuperado de: http:/ /www.eltiempo.com/bogota/las-desventajas-deser-musico-en-bogota/14208737. 2014.

[2] La vitrola. Música Creativa. Recuperado (abril 10 de 2018) disponible en: http:/ / lavitrola.com.co/ nosotros/. 2010.

[3] Tutoque. Recuperado (marzo 25 de 2018) disponible en: https:/ / www.tutoque.co/quienes-somos/

[4] J. Guerrero, Amenizar. Música para el éxito. Recuperado (marzo 13 de 2018) disponible en: http:/ / amenizar.musicaparaelexito.com/

[5] QuieroMusicos. Recuperado (febrero 4 de 2018) disponible en: http:/ / quieromusicos.com/

[6] El País. Conozca Serenatapp, la aplicación para contratar serenatas a través internet. Recuperado de: http://www.elpais.com.co/cali/conozcaserenatapp-la-aplicacion-para-contratar-serenatas-a-traves-internet.html. 2015.

[7] O. I. Osorio, Músicos y serenatas. Recuperado (enero 16 de 2018) disponible en: http://musicos yserenatas.com/Quienes\%20somos.html. 2012.

[8] Mis mariachis. Recuperado de: http://misma riachis.com/. 2017.

[9] Mariappchi. Recuperado (marzo 23 de 2018) disponible en: https:// mariappchi.mx/

[10] Mercado Libre. Músicos y cantantes. Recuperado (abril 12 de 2018) disponible en: https:/ / servicios. mercadolibre.com.ar/fiestas-y-eventos/entretenimiento/shows-animaciones/musicos-cantantes/ 
[11] Olx. Músicos. Recuperado (abril 9 de 2018) disponible en: https://lima.olx.com.pe/nf/search/ musicos

[12] Ramasso Productora. Recuperado (febrero 18 de 2018) disponible en: http:/ / robertoramasso.com/ contrataciones/contratar-musicos/

[13] BUSK. Recuperado de: https://busk.co/blog/ busking-tips-tricks/music/. 2016.

[14] A. López Gaona, El modelo Entidad-Relación. Recuperado (abril 28 de 2018). Disponible en: http:/ /hp.fciencias.unam.mx/ alg/bd/er.pdf

[15] F. Berzal, UML. El lenguaje unificado de modelado. Grady Booch, Jim Rumbaugh e Iva Jacobson. Recuperado (abril 28 de 2018). Disponible en: http:/ /elvex.ugr.es/decsai/java/pdf/3E-UML.pdf

[16] M. Fowler \& K. Scott, Los casos de Uso. UML gota a gota, cap. 3, 49-53. México: ADDISON WESLEY LONGMAN DE MÉXISO S.A. 1999.

[17] V. Fernández Alarcón, Modelado de casos de uso. Desarrollo de sistemas e información, Una metodología basada en el modelado, cap. 7, 131-133. Barcelona: Ediciones UPC. 2006.

[18] C. Larman \& P. Hall, Diagramas de Secuencia del Sistema Contratos de las operaciones del sistema, glosario y paquetes. UML y patrones. Edición 2. 2003.

[19] Departamento de Lenguajes y Sistemas Informáticos, Universidad de Sevilla. Introducción a las aplicaciones web, p. 1-4. Sevilla. Recuperado de: http:// www.lsi.us.es/docencia/get.php?id=854 . 2004

[20] M. Peñafiel, Definición de Aplicación Web. Escuela Superior Técnica de Chimborazo, p. 1-7. Recuperado (abril 20 de 2018). Disponible en: https:/ / es.scribd.com/doc/136052164/APLICACIONESWEB-pdf

[21] L. Florido Benítez, Marco Conceptual del Mobile Marketing y App. La implementación del mobile marketing como herramienta multidisciplinar en el sector turístico y aeroportuario, cap. 1, p. 19-44. Málaga. Recuperado de: http:/ / www.eumed.net/ libros-gratis/2016/1539/aplicacion.htm. 2014.

[22] J. Eguíluz Pérez, ¿Qué es JavaScript? Introducción a Java Script, cap. 1, p. 5. Recuperado de: http:// www.jesusda.com/docs/ebooks/introduccion_ javascript.pdf. 2008.

[23] T. Navarrete, Introducción. El lenguaje JavaScript, cap. 1, p. 1. Recuperado de: http://www.dtic. upf.edu/ tnavarrete/fcsig/javascript.pdf. 2006.

[24] M. A. Álvarez, ¿Qué es HTML? Llegó el momento de hablar sobre HTML, el lenguaje con el que crean las páginas web. Recuperado de: https:/ / desarrollo web.com/articulos/que-es-html.html. 2001.
[25] M. Palomo Duarte \& I. Montero Pérez, Introducción. Programación en PHP a través de ejemplos Recuperado (abril 28 de 2018). I, cap. 1, p. 1. España. Disponible en: http:/ / servicio.uca.es/software libre/publicaciones/apuntes_php

[26] J. Eguíluz Pérez, ¿Qué es CSS? Introducción a CSS, cap. 1, p. 5. Recuperado de http:/ / www.jesusda. com/docs/ebooks/introduccion_css.pdf. 2008.

[27] J. Sánchez, Introducción. MySQL guía rápida (Versión para Windows). Recuperado de: http:// www.cartagena99.com/recursos/programacion/ apuntes/mysql.pdf. 2003.

[28] Developers. Android Studio. Recuperado de: https://developer.android.com/studio/releases/ ?hl=es-419. 2018.

[29] J. Eguíluz Pérez, Introducción a AJAX. Introducción a AJAX, cap. 1, p. 5. Recuperado de: http:/ / www.jesusda.com/docs/ebooks/introduccion_ ajax.pdf. 2008.

[30] J. C. Conde Ramírez, Introducción a JSON. Web Technologies. Recuperado (abril 28 de 2018) Disponible en: http:/ / climate.cs.buap.mx/condeJC/ Cursos/Material/WebTechnologies_/Notas/ D1_JSON.pdf

[31] M. Manchego, Método POST. Diferencia entre envío GET Y POST. Recuperado de: http:/ / www. miguelmanchego.com/2010/diferencias-entre-envio-get-y-post/. 2010.

[32] V. J. Eslava Muñoz, Patrones de arquitectura: Arquitectura Modelo-Vista-Controlador. El nuevo PHP, conceptos avanzados, cap. 8.1, 109-112. España: Bubok Publishing S.L. Recuperado de: https:/ / books.google.com.co/books?id=NSj3A QAAQBAJ\&pg $=$ PA109\&dq $=$ modelo + vista + con trolador\&hl $=$ es\&sa $=$ X\&ved $=0$ ahUKEwispc-pq_aAhXCulMKHXIlBhkQ6AEIRDAF\#v=onepage \&q=modelo \%20vista \%20controlador\&f=false. 2013.

[33] M. Herrera Castellanos, Fórmula para cálculo de la muestra poblaciones finitas. Disponible en: https:/ /investigacionpediahr.files.wordpress. com/2011/ 01/formula-para-cc3a1lculo-de-la-muestra-poblaciones-finitas-var-categorica.pdf. 2011.

[34] Gobierno de España. Visualización de Datos: Definición, tecnología y herramientas, cap. 1, 4-5. Ministerio de Industria, Energía y Turismo. Disponible en: https:/ / datos.gob.es/sites/default/files/doc/ file/informe_herramientas_visualizacion.pdf. 2016.

[35] Y. Gallardo De Parada, A. Moreno Garzón, Serie: APRENDER A INVESTIGAR. Módulo 3, Recolección de la información. Instituto Colombiano para el fomento de la Educación Superior, cap. 6: Técnicas para la recolección de información primaria, 
56-64. Disponible en: http://www.unilibrebaq. edu.co/unilibrebaq/images/CEUL/mod3reco leccioninform.pdf. 1999.

[36] C. Mera Amezquita, Guía para interactuar con stakeholders en el proceso de ingeniería de requerimientos, Anexo 1, Listado de técnicas de levantamiento de información, 6. Disponible en: http:/ / pegasus.javeriana.edu.co/ CIS1010IS06/descar-
gas/Anexos/Marco\%20Teorico/Anexo\%203.\% 20Listado_de_Tecnicas_de_levantamiento_de_ Informacion.pdf. 2009.

[37] A. Medina, Introducción a MD5. MD5 - Definición y Aplicaciones. Seguridad en Redes. Recuperado de: http:/ / seguridadredesmedina.blogspot.com. co/2009/10/md5-definicion-y-aplicaciones.html. 2009. 